\title{
The joint sets on the Lilstock Benches, UK. Observations based on mapping a full resolution UAV-based image
}

\author{
Martijn Passchier**1, Cees W. Passchier ${ }^{2}$, Christopher Weismüller ${ }^{3}$, Janos L. Urai ${ }^{1}$ \\ ${ }^{1}$ Tectonics and Geodynamics, RWTH Aachen University, Lochnerstrasse 4-20, D-52056 Aachen, Germany, \\ www.ged.rwth-aachen.de; Passchier - Orcid 0000-0001-9925-1739; Urai - orcid 0000-0001-5299-6979 \\ email: martijn.passchier@yahoo.de \\ email: j.urai@ged.rwth-aachen.de \\ 2 Tektonophysik, Johannes Gutenberg University of Mainz, D-55099 Mainz, Germany. Orcid 0000-0002-3685- \\ 7255 \\ email: cpasschi@uni-mainz.de \\ ${ }^{3}$ Neotectonics and Natural Hazards, RWTH Aachen University, Lochnerstrasse 4-20, D-52056 Aachen, \\ Germany, www.nug.rwth-aachen.de \\ email: c.weismueller@nug.rwth-aachen.de \\ *corresponding author: martijn.passchier@yahoo.de
}

This preprint was submitted to the Journal of Structural Geology for peer review. 


\title{
1 The joint sets on the Lilstock Benches, UK. Observations \\ 2 based on mapping a full resolution UAV-based image
}

\author{
3 Martijn Passchier*1, Cees W. Passchier ${ }^{2}$, Christopher Weismüller ${ }^{3}$, Janos L. Urai ${ }^{1}$ \\ $4{ }^{1}$ Tectonics and Geodynamics, RWTH Aachen University, Lochnerstrasse 4-20, D-52056 Aachen, Germany, \\ 5 www.ged.rwth-aachen.de; Passchier - Orcid 0000-0001-9925-1739; Urai - Orcid 0000-0001-5299-6979 \\ $6{ }^{2}$ Tektonophysik, Johannes Gutenberg University of Mainz, D-55099 Mainz, Germany. Orcid 0000-0002-3685- \\ $7 \quad 7255$
}

$8{ }^{3}$ Neotectonics and Natural Hazards, RWTH Aachen University, Lochnerstrasse 4-20, D-52056 Aachen,

9 Germany, www.nug.rwth-aachen.de

10 *corresponding author: martijn.passchier@yahoo.de

11 Keywords: joint, Lilstock, joint abutment, UAV, fracturing

12 Highlights

13 - Full-resolution UAV-based image of the joint set of the classic Lilstock benches (UK)

14

- Layer-bound joints are fully imaged over an entire large outcrop

- Up to eight sets of joints occur in a single limestone layer

- Jointing is laterally heterogeneous in the same layer and different between layers

- Phases of sealing accompanied the evolution of older joints at Lilstock

Abstract

Outcrop studies of fracture networks are important to understand fractured reservoirs in the subsurface, but complete maps of all fractures in large outcrops are rare due to limitations of outcrop and image resolution. We manually mapped the first full-resolution UAV-based, Gigapixel dataset and DEM of the wave-cut Lilstock Benches in the southern Bristol Channel basin, a classic outcrop of layer-bound fracture networks in limestones. We present a map of the patterns and age relationships of successive sets of joints in dm-thick limestone layers separated by claystone beds. Using interpretation criteria based on crosscutting relationships, abutting and joint length, up to eight successive sets of joints were mapped. Results show that joint geometry and interrelations are fully resolved in the whole outcrop. Different joint sets have unique characteristics in terms of shape, orientation, spatial distribution and cross-cutting relations. The presence of low-angle crossings and junctions of joints suggest periods of partial joint sealing and reactivation. The dataset and interpretations are proposed as an outline for large scale, complete fracture network mapping to test digital fracture network models. 
Fractures in layered sedimentary rocks are amongst the most common and most intensely studied structures in geology, present in nearly every outcrop (Pollard and Aydin, 1988; Price and Cosgrove, 1990; Twiss and Moores 1992; Rawnsley et al., 1998, Belayneh, 2003, 2004; Peacock, 2004; Fossen 2016; Laubach et al., 2019). Fracture networks form important reservoirs and pathways for mineralizing fluids, hydrocarbons and water in sedimentary basins (Berkowitz, 2002; Bonnet et al., 2001; de Dreuzy et al., 2012; Olson et al., 2009; Tsang and Neretnieks, 1998; Pyrak-Nolte and DePaolo, 2015). Their density, spacing, orientation and interrelation has therefore been a common subject of study of structural geology (Dyer, 1988; Dershowitz and Herda, 1992; Mandl, 2005; Peacock et al., 2018). To model fluid flow in fractured reservoirs, the 3D fracture network must be predicted in volumes of rock, large enough to be representative. Such models should be based on reality, and data are therefore needed on the geometry of natural fracture networks. Since most outcrops where fracture networks can be observed are small, analysis of such networks has mostly been done by hand or on small photo compilations for small volumes of rock (Belayneh and Cosgrove, 2004; Loosveld and Franssen, 1992). This is useful, but in order to obtain realistic models, it should be tested whether such results still apply to the arrangement of fractures in larger volumes of rock. For this purpose, large rock volumes, in the form of large outcrops in well-exposed domains should be analysed. Unmanned aerial vehicle (UAV)-based photography has recently started to provide data for such largescale models (Pollyea and Fairley, 2011; Menegoni et al., 2018; Wüstefeld et al., 2018). The first aim of this study was to investigate if mapping of large outcrop surfaces with thousands of joints contributes beyond the study of smaller scale domains. We demonstrate, using an example from the UK, that such mapping, using UAVs, can indeed provide data that cannot be obtained from mapping small-scale outcrops. Such large-scale studies can be applied in coastal outcrops, and well-exposed domains in mountain and desert areas on Earth and is particularly promising in planetary science. A second aim of this paper is to investigate to what extent fracture networks from large outcrops can be subdivided into sets and generations, and if traditional criteria of relative age and overprinting relations can be applied to such fracture networks.

The Lilstock Benches in the British Channel in the UK (51 $1^{\circ} 12.166^{\prime}$ N, $003^{\circ} 12.014^{\prime}$ W; Fig. 1) are a classic outcrop of faults and joint networks. The Benches are part of the Lilstock anticline, a large intertidal outcrop of subhorizontal layers of thin-bedded Jurassic limestone alternating with claystone layers. The limestone layers contain a dense pattern of joints, augmented by weathering, that have been studied since 1990 (Loosveld and Franssen, 1992) by several groups (section 1.2; e.g. Peacock and Sanderson, 1991; Dart et al., 1995; Rawnsley et al., 1998; Peacock, 2004; Glen et al., 2005; Gillespie et al., 2011). Most studies were done on a small part of the extensive coastal platforms or used data of low resolution (Fig. 1), and no attempt has been made to make a full inventory of the complete joint network in the whole outcrop. One of the implicit assumptions in many such studies is that a small outcrop will be representative for a larger domain. In this paper, building on first results of Weismüller et al., 2020a, we show that this provides insufficient information to fully characterise the fracture network, and oversimplifies the deformation history. We focussed this study on the Lilstock outcrop in order to investigate how a joint pattern as at Lilstock can be mapped using a large UAV-based ortho-rectified photomosaic, to (i) define 66 criteria for determining the age relationship of the joints, and (ii) to provide a first interpretation of the geometry and interference history of the entire joint network. The orthomosaic we compiled covers a $350 \times 700 \mathrm{~m}$ area of 
the Lilstock Benches with a pixel size of $7.5 \mathrm{~mm}$, sufficient to resolve all joints for the first time in a compilation of $4 * 10^{9}$ pixels. The present paper is part of three publications using the dataset (Weismüller et al., 2020a, b). Weismüller et al. (2020a) compares complete fracture maps from manual and automatic tracing methods, analyses geometry and topology of the fracture networks and provides an evolutionary model based on age relationships similar to the ones presented here. Weismüller et al., (2020b-open access) presents the orthomosaic we used for joint interpretation to allow verification of our results. A shapefile is also attached as supplementary material to the present paper. In a follow-up paper we will present a map based on automated interpretation of all fractures.

\subsection{Terminology}

We use the terminology as follows (Pollard and Aydin, 1988; Price and Cosgrove 1990; Twiss and Moores 1992; Fossen 2016; Laubach et al., 2019): fractures are sharp planar discontinuities in otherwise massive rock; joints are narrow opening-mode fractures (Laubach et al., 2019) with very small (less than one mm) or no lateral displacement, while faults have displacement exceeding $1 \mathrm{~mm}$ parallel to the fracture. Cohesion along fractures may be negligible or approach cohesion of the wall rock, depending on the degree of (partial) sealing by mineral growth in the fracture (Laubach et al., 2019). Sealing may occur at different stages in the development of fractures after their initiation. We reserve the term vein to fractures sealed with a macroscopically visible thickness of crystalline material different from the fabric of the adjacent rock. Joints may be unsealed, without cohesion, or sealed by a minor amount of crystalline material providing cohesion (Pollard and Aydin, 1988; Price and Cosgrove 1990; Twiss and Moores 1992; Fossen 2016; Laubach et al., 2019). In our study, we mostly limit ourselves to joints. We did not make direct observations to determine if joints were sealed during part of their development, especially since sealing can be patchy or temporary: we have not investigated the microstructure of joints but have restricted ourselves to the large-scale geometry of macroscopically visible shape, orientation and intersection relations.

\subsection{Lilstock outcrop - geology}

The Bristol Channel Basin (West Somerset, UK) has experienced three main stages of deformation (Dart et al., 1995). A first stage created east-west striking normal faults, followed by north-south directed compression that led to partial inversion of the normal faults and folding. A third stage of north-south compression resulted in NESW striking sinistral strike-slip faults. Extension is thought to be lower Jurassic and Cretaceous in age, while subsequent inversion and strike-slip deformation are interpreted to be Tertiary (Dart et al., 1995; Glen et al., 2005). Burial was to a depth of about $1.5 \mathrm{~km}$.

The Lilstock outcrops present weakly deformed Jurassic (blue Lias) sediments with large scale open folds, faults, veins and joints formed during burial and uplift (Fig. 2b). Dm-scale limestone layers alternate with claystone beds of more variable thickness, between $4-71 \mathrm{~cm}$. The thickness of the limestone and claystone layers is laterally consistent. A single asymmetric E-W trending open anticline affects the entire Lilstock outcrop with the hinge zone located directly south of the main fault (Fig. 1). The southern limb of the fold rapidly steepens to the south while the northern limb of the anticline is less steep and outlines platforms of single exposed horizontal layers 
known as "benches" (Fig. 1). The anticline is attributed to the second regional deformation phase of north-south compression (Dart et al., 1995).

\subsection{Previous work on fractures in Lilstock}

Papers on the joints in Lilstock usually discuss small areas of this large outcrop. Key publications discuss the relation of joints to faulting (Peacock and Sanderson, 1991; Rawnsley et al., 1998; Gillespie et al., 2011), vein formation (Peacock, 2004) and basin inversion (Dart et al., 1995; Glen et al., 2005). The local joint pattern is complex and formed in several sets due to overprinting generations of deformation (Dart et al., 1995). The geometry of the joints has been extensively studied on selected parts of the outcrop (Gillespie et al., 2011; Peacock, 2004). Some of the earliest work was by Loosveld and Franssen (1992) who used a helicopter to photograph part of the outcrop and identified up to six sets of joints. This was followed by Rawnsley et al., (1998), who identified the well-known fans of first-set joints converging on asperities on faults. Engelder and Peacock (2001) and Belayneh and Cosgrove (2004) interpreted five to six sets of joints, describing their geometry and evolution. Figure 1 shows the approximate location of these studies, compared with the area covered in this paper. Peacock (2001) showed that there is a temporal relation between joints, faults and veins in the Lilstock outcrop (Peacock, 2004; Spruženiece et al., 2020, 2021). Veins in Lilstock limestones have been studied by Caputo and Hancock (1999) and Cosgrove (2001). Faults were the subject of numerous publications. This includes strike-slip faults (Peacock and Sanderson, 1995; Willemse et al., 1997; Kelly et al., 1998), normal faults (Davison, 1995; Nemčok and Gayer, 1996), their association with relays (Peacock and Sanderson, 1991, 1994) and normal fault inversion (Brooks et al., 1988; Chadwick, 1993; Dart et al., 1995; Nemčok et al., 1995; Kelly et al., 1999). Stress models inferred from the surface morphology of joints or aerial photographs have been studied by Belayneh (2004) and Gillespie et al., (2011). Belayneh (2003) and Belayneh et al., (2006) performed fluid injection simulation studies on the fracture network.

\section{Materials and Methods}

\subsection{UAV data acquisition}

The entire Lilstock outcrop was photographed at low tide on 19 - 20 June 2017. Since high tide covers the outcrop, we started one day after neaps with a tidal range of $2.69 \mathrm{~m}$ to $9.69 \mathrm{~m}$. The outcrop was surveyed on foot after data acquisition by UAV to select key points for measurements and to take photographs with sub-millimetric resolution. The UAV used was a Phantom 4 model by SZ DJI Technology Co., Ltd with a 12.4-megapixel camera. Joints were photographed from an altitude of $20-25 \mathrm{~m}$ to obtain sufficient resolution to see all joints present. Photos were merged into high-resolution digital orthomosaics using PhotoScan by Agisoft. These images have a pixel size of $7.5 \pm 1 \mathrm{~mm}$ (Fig. 2c). Ground truthing was done against sub-mm resolution photographs of selected locations on the surface to validate our identification of all joints, which are enhanced in visibility by wave erosion. Further details on the method used are published in Weismüller et al., (2020a) and the original orthomosaic is available in Weismüller et al., (2020b) . 
We extracted joint lengths and orientations for single joint traces using QGIS. Statistical values for joint lengths in Table 2 were calculated using the NetworkGT plugin (Nyberg et al., 2018), which was also used to generate the length weighted rose diagrams in Figure 6a. To further investigate the length distribution of joints within a certain set, joint lengths were plotted as histograms in combination with their cumulative length distribution in Figure $6 \mathrm{~b}$ and as box and whisker plots in Figure 8.

To quantify the spacing between joints in a set, we used several scanlines oriented orthogonally to the mean joint orientation of the respective set. These scanlines are labelled 1-3 in Figure 7 and in the text, with the relative joint set number, e.g. J1_1, J1_2. The position of the scanline was chosen to overlap with an area where the investigated array of joints is abundant, and the underlying base map of the fractured pavement is of good quality. This allowed detailed estimation of the spacing between joints. The position of joints of the respective sets were marked along the scanlines. The intersections of all interpreted joints along a scanline were then used to calculate the distance from the first joint to the other joints along a scanline, as visualized in Figure 7. The distances between neighbouring joints (spacing) were calculated and used to infer further statistical values, presented as spacing in Table 2 and Figure 7.

151 The joints of set $\mathrm{J} 1 *$ are curved and therefore vary in orientation depending on the position along the trace where its orientation is measured. The overall orientations of these curved joints were defined as the orientation along a straight line from tip to tip. To further quantify the geometry of $\mathrm{J}^{*}$ joints, we calculated their curvature as the quotient of the true length along the joints trace and the shortest distance between the tips. Curvature values of single joints are plotted on a map as a colour gradient from white, for a curvature of 1 for a straight line, to red for the relatively highest curvature value (Fig. 11). To investigate possible correlations between geometrical attributes of $\mathrm{J} 1$ * joints, orientation and length as well as orientation and curvature were plotted against each other in Figure 12.

\subsection{Joint mapping criteria}

160 For this study, we mapped one complete Bench, part of layer IV in the local stratigraphy, to test to what extent the 161 sequence of joints can be analysed in a completely exposed layer, and if this sequence is laterally consistent (Fig. 162 1). The exposed surface of this layer (named "Bench IV") was naturally separated into two areas (W and E) by an 163 erosion gully and a thin strip of rock in which joints cannot be properly attributed (Fig. 1). The photo mosaics were mapped in detail with a maximum resolution of $7.5 \pm 1 \mathrm{~mm}$ and interpreted in terms of age relations and overall shape. Images were manually interpreted using ArcGIS. Joints were traced as polygons over their complete length. Joints were mapped and subdivided into sets using the following "traditional" criteria:

(1) Joints that are straight or slightly curved but continuous despite crossing other joints, are interpreted as one joint, of one set.

(2) Mapped joints are hierarchically assigned to specific relative age sets in relation to other sets of joints by analysis of the intersections between joints. These intersections can either be of " $\mathrm{X}$ " shape (crossing) or " $\mathrm{T}$ " shape (abutting) (Fig. 2a). Abutment is the main argument to assign relative ages to the joints, while $\mathrm{X}$-intersections do not provide such information. A secondary argument to assign 

the conflict can be explained.

Attributes such as length and orientation were extracted from ArcGIS and plotted to illustrate basic statistics (Figs. 6-8). Although all joints were use in the profiles to determine joint spacing, the maps (Figs. 3, 5a, 9, 11, S1) only show every second joint of each set, since mapping all joints in the full outcrop would not have been possible within the time available for this project (interpreting the presented results took 200 hours). In a previous paper by Weismüller et al., (2020b) we have shown that automatic interpretation of all joints in the image is possible, but not their assignment to different generations. In a follow up paper (Prabhakaran et al., submitted, https://doi.org/10.31223/X5B61Z) a full interpretation of all joints will be presented. The complete interpreted map is shown in Figures $4 \mathrm{f}$ and S2. The youngest joint set (J8) was only mapped in one sub-area (Fig. $4 \mathrm{f}$ ) since it is different from other joints in the area, having a near random orientation and being so closely spaced that it cannot be shown on the same scale as the older, longer joints.

\section{Results}

\subsection{Joint imaging}

The Lilstock outcrop is extraordinary, both in the number and density of exposed joints, and in the nature of their weathering. Because of the local high tides, joints weather at the surface to a U-shape that allows imaging them with the resolution of our images (Fig. 2b-e). This weathering pattern is observed for joints in every direction while depth depends on the time period of exposure. Freshly exposed limestone layers show less weathering, although joints are still visible on our images.

\subsection{Joints - Results of digital outcrop interpretation}

\subsubsection{Area $W$}

The Western Area (Area W) of Bench IV (Figs. 1, S1) contains eight sets of joints, some of which are only present in part of this area (Fig. 3). The joint sets were dated with respect to each other using the criteria described above. In the westernmost part of Area W, five sets of joints were recognized (Figs. 4c, 5; Table 1). The first set (J1) has long joints that cross the entire Area W with a NW-SE trend and even continue into layers II and III to the north (Figs. 3, 6). They are mostly between 7 and $22 \mathrm{~m}$ long but can reach up to 55 metres (Figs. 6, 8). In the westernmost part of Area W, the joints are abutted by a second set, J2, at a low angle to J1 (Fig. 4a). J2 joints have the same length distribution as J1 joints (Figs. 6, 8) but are more closely spaced (Figs. 7, 8) and mostly straight, bending only close to their termination against J1 joints to end in a T-shaped abutment (Fig. 4a). Some J2 joints impinge upon other $\mathrm{J} 2$ joints. The angle between $\mathrm{J} 1$ and $\mathrm{J} 2$ joints decreases eastwards by a change in orientation of the J1 joints, while $\mathrm{J} 2$ retains its orientation, till both sets of joints are subparallel. In the centre of Area $\mathrm{W}, \mathrm{J} 1$ and $\mathrm{J} 2$ joints can no longer be distinguished and are all mapped as $\mathrm{J} 1$ joints. Both sets of joints disappear towards the east of Area W (Fig. 3). 
NE-SW trending J3 joints are short and closely spaced joints although their spacing can vary (Figs. 4c, 7,8). They are mostly less than $5 \mathrm{~m}$ in length (Figs. 6, 8). J3 joints occur over most of Area $\mathrm{W}$ but disappear towards the NE (Fig. 5). J4 joints make a small angle with $\mathrm{J} 3$ joints and are even shorter than these, usually less than $3 \mathrm{~m}$ long (Figs. 5-8). They differ from J3 joints in being much further spaced apart (Figs. 7,8). J4 sets are present throughout Area W (Figs. 3, 4d).

Three younger sets of joints, J5-J7, occur exclusively in the NE part of Area W (Figs. 4d, 5). J5 joints are subparallel to J4 joints of this area (Table 1; Fig. 6) but locally impinge on J4 joints with a T-junction, proving their relative age. J5 joints can be further distinguished from $\mathrm{J} 4$ joints by their greater length and spacing (Figs. 68 ), which is consistent throughout Area W, and their slightly curved geometry. J4 joints tend to be perfectly straight, similar to J2 and J3 joints (Fig. 4d). J6 joints trend NW-SE and are strongly curved in contrast to older sets (Fig. 4d,e). They impinge on J4 and J5 joints with a T-junction confirming their relative age. They are shorter and less widely spaced than J5 joints, resembling J4 joints in that aspect (Figs. 6-8). J7 joints are also curved, trend approximately NNW-SSE and abut all previous sets in T-shapes in locations where J5 and J6 joints intersect (Figs. $3,4 d, e)$. They are very short with relatively narrow spacing (Figs. 6-8). Length weighted rose plots (Fig. 6) show that J1-J5 joints have little variation in orientation of less than ca. $20^{\circ}$ within each set and show an anticlockwise change in orientation from NW-SE for $\mathrm{J} 1$ to SW-NE for J5 (Figs. 3, 5, 6). J6 and J7 joints have quite different orientations (Fig. 6) and tend to be more curved than earlier sets. J7 varies considerably in orientation over its range (Figs. 4d,e; 6, 8).

The youngest joints (J8) are very different from all older joints (Fig. 4f). They have variable orientation, abutting against all older joints and never crossing them (Figs. 4f, S2). The density of J8 joints varies between stratigraphic layers of different thickness, creating different sized limestone blocks. However, block size also depends on the density of older set joints. Stratigraphic layer IV (Bench IV) is twice as thick as layer III (Fig. 1), but the limestone blocks delimited by J8 joints in Bench IV are smaller than in the adjacent layer, while the opposite would be expected. This could be due to the density of older joints that is much higher in layer IV than in the stratigraphic layers above, creating smaller blocks.

\subsubsection{Area $E$}

The eastern part of the investigated Bench IV, Area E, comprises a large, exposed bench of the same layer IV as in Area W, separated from it by a gully and a domain where joint sets cannot easily be attributed. (Figs. 5, 9; Table 1). Labelling in Area $\mathrm{E}$ of the bench follows that of Area W, where more sets are present, with the addition of an asterisk: joint sets recognised in Area $\mathrm{E}$ are labelled $\mathrm{J} 1^{*}, \mathrm{~J} 4^{*}, \mathrm{~J} 5^{*}, \mathrm{~J} 6^{*}$ and $\mathrm{J} 8^{*}$. Because of their orientation, spacing and geometry, they are thought to correspond to joints with the same number in area $\mathrm{W}$.

$\mathrm{J} 1 *$ joints occur locally and show pronounced fanning, converging on a fault (Gillespie et al., 2011) and thinning out towards the centre of the area (Figs. 5,9). The same relation can be found, with smaller fans of $\mathrm{J} 1 *$, in other stratigraphic layers, always related to the main fault (Figs. 5, S1). Single J1* joints cross most of the Bench in a

240 SE-NW direction. Shorter joints can be observed to abut joints of the same set, continuing in the same direction. 241 Besides a main fan in the SE, two smaller fans of $\mathrm{J} 1 *$ joints are visible on Bench IV as well (Figs. 5, 9). In the 
westernmost part of Area E, the $\mathrm{J} 1 *$ joints have a trend of $140-150^{\circ}$ and T-junctions show them to be older than J4*

$244 \mathrm{~J} 4 *$ joints strike in the same direction and show the same characteristics of orientation, curvature, shape, length 245 and spacing as J4 joints of Area W, being the only example of joints that are easy to correlate over the entire Bench 246 IV (Figs. 5-9). J4* occurs throughout Area E, while other sets occur in a patchy manner.

$247 \mathrm{~J} 5 *$ - and $\mathrm{J} 6 *$ joints are spatially separated, with only a small area of overlap where they show their relative age 248 through abutment (Figs. 5, 9). J5* is restricted to the western part of Area E but seems to cross into stratigraphic 249 layer III north of Area E (Figs. 5, 9). J6* and J4* joints abut each other in T-intersections with equal frequency 250 (Fig. 10a). This would seem to contradict the described method of age determination through T-intersections. 251 However, since $\mathrm{J} 4 *$ joints are clearly and consistently abutted by $\mathrm{J} 5 *$ joints, and these $\mathrm{J} 5 *$ joints in turn are abutted 252 by J6* joints, the age relation can be indirectly determined (Fig. 10b). J5* joints are considerably shorter than J5 joints in Area W. They trend NE-SW but are slightly curved and show a considerable variation in orientation due 254 to fanning (Figs. 6, 8, 9). J6* joints trend NW-SE and are similar to J6 joints in length and orientation. The youngest set $(\mathrm{J} 8 *)$ in Area E is similar to J8 in Area W, occurring perpendicular to older joints. However, Area E presents domains of approximately $10 \times 10 \mathrm{~m}$ with only few $\mathrm{J} 4 *$ and many $\mathrm{J} 8 *$ joints, resulting in joint networks made up of nearly only $\mathrm{J} 8 *$ (Fig. 5c)

258 The transitional domain of Bench IV between areas $\mathrm{W}$ and $\mathrm{E}$ contains numerous joints in various directions, but 259 impingement relations are not clear since older joints cannot be followed for a long distance in the narrow Bench 260 (Figs. 1, 5). The reason is probably that joints of different sets happen to lie at a small angle with each other, and 261 older joints may have been reactivated to impinge on younger joints. This makes age relations unclear. In Areas $262 \mathrm{~W}$ and $\mathrm{E}$, intermediate sets of joints occur which allow distinction of joint sets.

\subsubsection{Other layers}

264 In other layers than Bench IV, joint set sequences and orientation may deviate from those in Bench IV, but relations 265 have not yet been mapped. For example, in layers south of Area W, below Bench IV, the locally oldest set of joints 266 follows the same orientation as the hinge line of the main fold (Fig. 5). This parallelism to the hinge of the fold 267 appears over a large area and across multiple stratigraphic layers. Different stratigraphic layers seem to have 268 different sets of joints. While most layers have 2-3 sets, Bench IV shows up to 8 sets of joints with a maximum of 269 approximately six sets being present on $10 \mathrm{~m}$ scale surfaces (Fig. 5c; cf. Lorenz et al., 2002).

\subsubsection{Joint length}

271 Statistics of the mapped joint lengths for the entire Bench IV are shown in Table 2. The presented results should 272 be considered a first order estimate that might differ from the output of a complete interpretation of the entire 273 outcrop or complete interpretations within predefined domains. Therefore, it is important to view the presented 274 results in their entirety and to less emphasize single attributes. Minimum length values for all sets are conservative 275 because of censoring of the traces and the tracing method. 
Initial results show that sets J1, J2 and J5 are the groups with the overall longest joints of which J1 includes the overall longest joints and J7 the shortest in Area W (Table 2; Figs. 6, 8). In Area E, the longest joints are in set $\mathrm{J} 1 *$. The calculated skewness is positive for all sets, indicating that the joint length distributions (Fig. 6) are asymmetric with tails towards the right (longer fractures). This can also be observed in the histogram plots in combination with the cumulative length distribution that show that most fractures within a set are small (respectively within the set) and the respectively larger fractures are fewer, if not outliers, suggesting a typical power-law distribution of the joints in all sets (Fig. 6). The kurtosis (Table 2) also describes the shape of the length distribution. The small values for $\mathrm{J} 1, \mathrm{~J} 2, \mathrm{~J} 4, \mathrm{~J} 7, \mathrm{~J} 4 *$ and $\mathrm{J} 6 *$ indicate that the lengths are distributed close to the mean length of the set, while the higher values of $\mathrm{J} 3, \mathrm{~J} 5, \mathrm{~J} 6, \mathrm{~J} 1 *$ and $\mathrm{J} 5 *$ suggest distributions with a stronger peak around the mean.

\subsubsection{Joint spacing and curvature}

The intersections of joints within a certain set with a scanline are plotted in Figure 7. Scanlines vary in length because they were cut off according to the extent of the respective joint set. The distribution of the intersections along the scanlines reveals slightly different patterns that consist of: cases where joints are evenly distributed over shorter distances or sections along the scanline, but less evenly over the entire length of the scanline (e.g. scanlines J1_2, J2_2, J3_3) because of "breaks" where no joints intersect, or

iii) patterns that show sections with joints, divided by breaks without joints, and different frequencies of the joints within the sections where they are present (e.g. scanline J7_1).

In some sets, joints are either fanning as a set $\left(\mathrm{J} 1^{*}, \mathrm{~J} 5^{*}\right)$, or change strike direction gradually $\left(\mathrm{J} 1^{*}, \mathrm{~J} 5, \mathrm{~J} 7\right.$; Figs. 3 , $4,6,8,9)$. The curvature of $\mathrm{J} 1 *$ joints is the most pronounced, as shown in Figure 11. Joints with higher curvature are located at the margins of the fan structure where joints have a higher curvature than the ones in the centre of the structure. A plot of the orientation vs. length of single J1* joints (Fig. 12a) reveals no clear relation of the two values, as orientations spread over an interval of $100^{\circ}$ with similar lengths, something also suggested by the rose diagram in Figure 6. Also, the plot of curvature vs. orientation of the joints (Fig. 12b) does not reveal a clear relationship of these two attributes.

\section{Discussion}

This study presents a manually interpreted map of joints in the famous Lilstock Benches, based on a complete high-resolution digital image of the outcrop. Previous work has either used stitched photos of parts of the outcrop, or images without the resolution to resolve all joints. Preparing the image was possible because the joints are augmented by wave erosion, which allowed imaging all joints in this large outcrop with a UAV in one single day.

308 Comparison with close-up photos of selected sites with much higher resolution validates that the resolution chosen is indeed sufficient: all joints are visible on our image (Weismüller et al., 2020). Our observations are generally in 
agreement with existing studies, which have shown that the joints are younger than the faults and veins in the

311 outcrop, and developed during uplift, with stress concentrations at fault asperities during the development of the

312 first joint set, causing the well-known joint fans also present in other outcrops around the Bristol channel (Bourne

313 and Willemse, 2001; Maerten et al., 2018). However, our approach of mapping the entire outcrop enhances the

314 information that can be drawn from the observed joints, as outlined below.

\subsection{Robustness of interpretation}

316 In agreement with earlier studies, we found that, since younger joints do not deform or displace older joints, mapping of joint sets and distinguishing different sets is generally possible based on a few simple criteria (Peacock et al., 2018):

1. assigning joints to a specific set is by orientation, abutment relations and length: the longest joints are generally oldest.

2. joint intersections can be either of "X" or " $T$ " shape ( $\mathrm{X}$ and $\mathrm{Y}$ in Laubach et al., 2019). T-shaped geometries are the main argument to assign relative ages to the joints.

3. joints that are straight or slightly curved but continuous despite cross-cutting other joints in Xintersections, are interpreted as one joint.

325 Using these simple criteria, we could identify eight age sets of joints over Bench IV, more than in any earlier study

326 (Fig. 8). However, in a number of cases analysis based on these criteria gives problematic results, as discussed

327 below. To check the robustness of the interpretations, selected areas were digitally mapped by a second interpreter

328 using the same criteria, with very similar results. In Table 1 we compare the different joint sets interpreted in previous studies with the sets found in this project, as far as possible. The locations of the studied joints of previous publications are shown in Figure 1. Sets of joints presented in the literature but missing in this paper can be explained because these studies were done on a different bench. Although it is possible to recognise sets of joints, the nature of the structure imposes inherent problems that are outlined below.

\subsection{Sample size and number of joint sets}

334 Our study shows that it is not possible to fully understand the full joint set content of the Lilstock Benches by study of any small representative area (Fig. 5). We can give a more complete and more complex image of the structural content of one specific layer in the stratigraphy because of the larger extent or our database, Bench IV, compared to earlier studies. First analysis of the joint sets present in Bench IV show that although at least eight sets of joints are present over the entire Bench, several sets are always missing in smaller parts of the outcrop (Fig. $5 \mathrm{c})$. Figure $5 \mathrm{~b}$ shows the approximate boundaries of domains where different numbers of joints would be found in small sample areas of $25 \mathrm{~m}^{2}$. A small domain in the centre of Area $\mathrm{W}$ (about $2 \%$ of the Bench) has six sets of 341 joints that can be identified and relatively dated by abutting relations, while five sets can be found in four subareas 342 of Areas W and E (about 30\% of the Bench), although each of these has a different group of joints. Different 343 groups of joints are also found in subdomains with fewer joint sets (Figs. 3, 5, 9). A sample domain smaller than

$34425 \mathrm{~m}^{2}$ would show even fewer sets, and fewer abutting relations, so that relations of different sets would remain 
uncertain. Small outcrops can therefore never reveal the complete picture, although set J4/J4* can form a bridge between subsamples in Bench IV.

\subsection{Representativeness for joints in the subsurface}

348 Since joints have been observed at the surface, subject to strong weathering, the question is to what extent they are representative for joints found at depth, which have never been brought to the surface (Lorenz et al., 2002). In the worst case, the joints we observe would be near-surface generated structures without any significance for subsurface structures. The presence of up to eight subsequent sets of joints, each with its characteristic orientation, length and inter-distance relations, however, makes it unlikely that these all formed at or near the surface. The only joints that are most likely near-surface related or formed during uplift are the youngest set J8/J8*. These joints are the most numerous, in terms of total length of joints per $\mathrm{m}^{2}$, abut against older joints, and do not cross these, probably because these youngest joints formed during uplift when older joints had opened (Figs. 4f, S2). $\mathrm{J} 8 / \mathrm{J} 8 *$ joints have a highly variable orientation. This indicates that these joints formed in remaining unjointed islands until the layer was saturated, their orientation controlled by abutting against the surrounding older joints.

\subsection{Properties of the observed joint sets}

The oldest joints, $\mathrm{J} 1 / \mathrm{J} 1^{*}$, found in the SW and NE of Bench IV (Fig. 13), fan out from a number of discrete points on the faults and are continuous and longer than the outcrop dimensions (Figs. 3, 5, 9). In the domains between the joint fans in Area E, there are areas completely devoid of $\mathrm{J} 1 *$ joints (Fig. 5). The local absence of $\mathrm{J} 1 / \mathrm{J} 1 *$ joints could be due to lateral changes in the stress field or in lithology, but this cannot be resolved without sampling and focussed local studies. In Area W, J1 joints show a small angle to J2 joints. Towards the east, J1 gradually changes in orientation until it is indistinguishable from J2. In our interpretation J2 joints formed late during the J1 phase, when the local minimum stress in the west of the bench rotated slightly anticlockwise. Although J2 joints are only known from the western part of Area W, they may be distributed throughout Bench IV as a later set of J1 joints, which can only be recognised where they make an angle with older J1 joints. This problem is not inherent to joints; similar problems could be envisaged for the interference of different sets of folds and foliations in other areas. J1 and $\mathrm{J} 2$ are quite similar and, thus, might be grouped into a single generation, with single joints that have developed successively, but during the same event/stress field orientation. Joints of sets J3 to J5 show a further gradual anticlockwise rotation after J1-J2 from NW-SE to NE-SW and show an expansion of the area in which they develop to reach a maximum during J4 (Fig. 13). Despite the fact that J3 and J4/J4* joints partly develop into pristine areas where no older joints were present, they are of limited length (Fig. 8). J3 and J4/J4* joints are of similar length in areas with older $\mathrm{J} 1$ and $\mathrm{J} 2$ joints and in pristine areas, implying that the shorter length of the younger joints is not due to impingement on older structures, but defined by other factors. J5/J5* joints, however, are significantly longer again than $\mathrm{J} 3$ and $\mathrm{J} 4 / \mathrm{J} 4 *$, and crosscut earlier sets (Figs. 3, 8, 9). They occur in selected areas of the bench only (Fig. 13). J5* has a fanning distribution similar to but less extreme than J1/J1* joints (Fig. 9)

379 Sets J6/J6* and J7 have a significantly different orientation from preceding set J5 (Figs. 3, 8, 9) and occur in two limited areas. Possibly, conditions for joint generation were similar in part of the outcrop during propagation of 
J6-J7 in terms of the local lithology and layer thickness of Bench IV. Clearly, the break between sets J1-J5 and J6$\mathrm{J} 7$ is significant.

383 Joint spacing results show considerable variation in distribution, even within a certain set along different scanlines, or even variations in frequency along a single scanline (Figs. 7, 8). Despite this variation, spacing is relatively small for $\mathrm{J} 2, \mathrm{~J} 3, \mathrm{~J} 6$ and $\mathrm{J} 7$ joints, and larger for $\mathrm{J} 1 / \mathrm{J} 1 *$, $\mathrm{J} 4 / \mathrm{J} 4 *$ and $\mathrm{J} 5 / \mathrm{J} 5 *$. There is no clear relation between joint length and spacing (Fig. 8)

\subsection{X-intersections}

Most joint sets in this study can be classified as distinct joint age sets or generations because of systematic abutment of younger joints of similar orientation and length-spacing characteristics on older sets. Abutment is characterised by a T-junction, where the younger joint does not cross over an older one, while in other cases the younger joint changes direction close to the older joint, to impinge at a higher angle than the far-field orientation (Figs. 4, 10). Abutment is common when older joints are not sealed. Bench IV, however, shows many examples of intersections where joints cross in so called X-intersections (Figs. 4, 10). X-intersections provide no information on age relations unless the relative cross-cutting relation can be determined, but are interesting, since they provide constraints on stress conditions during joint interaction and on the nature of joint sealing (Renshaw and Pollard, 1995). In our dataset, X-intersections between joints can occur at a very small angle, down to $5^{\circ}$ (Fig. 10d). In Bench IV, X-intersections are especially common for the older sets of joints, and one joint can commonly cross several older joints of even multiple sets before finally abutting on a joint of an older set. The presence of such low angle $\mathrm{X}$-intersections is intriguing, because if joints are unsealed fractures, even with very high anisotropy of the horizontal stress, crosscutting is not possible at such a low angle (Renshaw and Pollard, 1995): instead, the younger joints would abut on the older ones without crossing over into the adjacent block. However, joints can cross older joints if sealing of the older joint partly restores the shear strength (Virgo et al., 2013, 2014, 2016; Laubach et al., 2019). If joints are completely invisible to the stress field because they are sealed with vein material of exactly the same strength and elastic modulus, joints can cross without any deflection. However, if mineralisation of joints is partial or if sectors of joints are immobilised by jogs, so that these parts remain open and fluid filled, joints may cross older ones with small deflections. In Bench IV of Lilstock, no macroscopic deflection is visible for most $\mathrm{X}$-intersections, and we propose that the older joints were at least partially sealed before the younger set crossed these. For most age sets, joints cross several older joints before impinging on one of the same sets they crossed. This implies that joints can propagate through partially sealed joints until they hit an unsealed section. The percentage of sealing in older joints can therefore be expected to influence joint length of younger sets. Nevertheless, we saw no difference in the length distribution of joints sets J3 and J4 between those propagating through previously jointed and unjointed terrain (Figs. 3, 4c,d, 9). Their characteristic length may be explained by the nature of the stress-field in Bench IV and the adjacent claystone layers, which must have been different from that during formation of the long, early joints $\mathrm{J} 1 / \mathrm{J} 1 *$ and $\mathrm{J} 2$. The excessive length of $\mathrm{J} 5$ joints compared to $\mathrm{J} 4$ and $\mathrm{J} 3$ can be partly due to the fact that these joints form in domains where only short $\mathrm{J} 4$ joints formed previously, with a locally relatively wide spacing (Figs. 3, 13). All older joints, however, seem to have refractured before the formation of $\mathrm{J} 8$ and $\mathrm{J} 8 *$ joints, which always abut on the older joints. An important conclusion from our observations is that, apart from $\mathrm{J} 8 / \mathrm{J} 8^{*}$, no set of older joints will exclusively block 
propagation of a younger set; apparently, (partial) sealing of joints is common in the subsurface. Microscopic investigation of un-weathered joints in the area could theoretically provide information on sealing in future studies.

\subsection{Polyphase joints - reactivation: problems with abutment relations}

422 Our observations on abutment relations confirm earlier observations in other areas, where joints belonging to one set may have formed in several time steps, that some continuous joints can be polyphase in nature (Pollard and Aydin 1988; Alzayer et al., 2015). An example is seen in J4* and J6* joints, which impinge on each other while the joint sets are clearly separated by J5* joints (Figs. 4e; 10a,b). Probably, some J4* joints were reactivated and restarted growing with a new segment in the same orientation, to impinge on older parts of newly formed $\mathrm{J} 6$ *

427 joints. This is a case where joints do not change orientation between active stages. Another observation showed two J1 joints that apparently stopped growing and were reactivated when $\mathrm{J} 2$ joints formed, with the new segment following the direction of the second set with a sharp kink (Fig. 4b). The result is a rhomb-shaped form defined by two sets of parallel J1 and J2 joints, mutually abutting. Polyphase joints can therefore be of two types: those that continue growing in the same direction, since the stress field is similarly oriented, and those that nucleate on the tip of older joints and propagate in a new direction. Such nucleation occurs in Bench IV up to an angle of at least $17^{\circ}$ (Fig. 4b). At larger angles the new, and in some cases, old segments can open and form a transition to pennant veins (Coelho et al., 2006) and wing cracks (Gonçalves and Einstein, 2013; Kolari, 2017). Finally, joints can nucleate in several directions at the same time. The youngest set of joints (Fig. 10c) shows an example where recursive abutting of joints created an "Escherian paradox" (Penrose and Penrose, 1958) where age determination based on abutment criteria fails. We interpret this to indicate that the four J8-joints marked in Fig 10c nucleated simultaneously and grew until abutting in the recursive set during uplift. This type of behaviour was not observed for older joint sets.

\subsection{Joint length and age}

441 Because of the size of the UAV survey, we were able to show that exceedingly long joints, up to $55 \mathrm{~m}$ in length, exist as the oldest sets in the outcrop area ( $\mathrm{J} 1 / \mathrm{J} 1^{*}$ and $\mathrm{J} 2$ ), while $\mathrm{J} 5$ joints reach $40 \mathrm{~m}$ in length (Figs. $\left.6, \mathrm{~S} 1\right)$. This

443 is problematic for other studies that use small outcrops or even drill cores for assessment of fracture networks.

444 Although fracture connectivity is widely considered to be the dominant factor for flow in fracture networks (Long 445 and Witherspoon, 1985), length is an important parameter in fluid flow in permeable sedimentary rock fracture, 446 especially in non-interconnected systems (Philip et al., 2005). The presence of such joints in the subsurface should 447 be considered. The fact that the longest joints in Lilstock are the oldest set, abutted by several later sets, implies 448 that they are not an artefact of near surface processes: they formed at the onset of joint formation in the rock 449 volume under investigation, and are an integral part of the original fracture content of the rock. Longer joints have also been observed elsewhere by Laubach et al. (2016) and efficient mapping of large outcrops as advocated in

451 this paper could be the only way to assess the importance of long fractures, and to find criteria to recognise them in cross-section in the subsurface. 
$454 \mathrm{~J} 1 / \mathrm{J} 1 *$ and $\mathrm{J} 5$ joints form fans, radiating from a fault on the southern side of the exposed part of Bench IV (Figs.

$4553,5,9)$. Rawnsley et al. (1998) has shown that the fans of J1* joints converge on asperities on faults. Some of the 456 long $\mathrm{J} 1 *$ joints are strongly curved. Short $\mathrm{J} 1 *$ joints are less sinuous than the longer ones, which might be due to 457 mechanical effects, e.g., segmental growth of longer fractures causing a higher curvature, or the tendency to fan 458 out and curve more within a larger distance from the source (in this case the proximate fault) that causes the local stress field leading to fracturing. The same may apply to J5* joints, which tend to be straighter and shorter than $460 \mathrm{~J} 1 *$ joints.

\subsection{The recognition of joint generations versus sets}

462

463

464

465

466

Although we were able to recognise eight sets of joints, it is unclear if these can be grouped into generations or deformation phases in the classical sense. Joint sets $\mathrm{J} 1 / \mathrm{J} 1 *$ and $\mathrm{J} 2$ seem to be closely related and to develop during a gradual change in stress field orientation. Further, joint sets J1-J5 show a gradual clockwise change in orientation from NW to NE trending (Fig. 8). On the other hand, J1 and J5 joints show curvature and fanning geometries, while the other joint sets $\mathrm{J} 2-\mathrm{J} 3$ and $\mathrm{J} 4 / \mathrm{J} 4 *$ are straight (Figs. 3, 9). Joints sets J6/J6* and $\mathrm{J} 7$ only occur locally and have different orientations as compared with older ones: they may at least form a separate generation (Figs. 5, 13). $\mathrm{J} 5 / \mathrm{J} 5 *$ joints may form the transition between these two main groups. J8/J8*, finally, is definitely quite different from the other joints, and forms a separate generation. The joint sets can therefore be grouped into four main age groups, $\mathrm{J} 1 / \mathrm{J} 1{ }^{*}-\mathrm{J} 2 ; \mathrm{J} 3-\mathrm{J} 5 / \mathrm{J} 5 *^{*} ; \mathrm{J} 6 / \mathrm{J} 6 *_{-} \mathrm{J} 7$; and $\mathrm{J} 8 / \mathrm{J} 8 *$. Although joints can be relatively dated in one location, it is uncertain how diachronous they are, even within the platform of layer IV. In this discussion, we have argued that mapping of small outcrops, or worse, drill cores, may provide insufficient information to correctly assess the fracture network present in any area, and tends to oversimplify the interpreted fracture history.

\section{Conclusions}

1) Using UAV-based photography and image processing, it is possible to obtain a sufficient resolution to characterise the full fracture network of the classic outcrop of the Lilstock Benches.

2) The Lilstock outcrop in the Bristol Channel shows evidence for eight sets of joints, up to six in each location on a $25 \mathrm{~m}^{2}$ sampling window. These sets are distinguished by a well-defined set of criteria.

3) Different stratigraphic layers have different sets of joints. Most layers have 2-3 sets and only one layer (IV), with maximum thickness, has eight sets and at least four generations.

4) It is impossible to recognise the full array of joint sets in small outcrops ( $25 \mathrm{~m}^{2}$ or smaller) in the Lilstock Bench IV: six sets is the maximum in any such domains. This places significant restrictions on the use of small outcrops or, worse, drill cores for the reconstruction of fracture networks.

5) Crosscutting of one set of joints by the next mostly occurs in older joint sets. The youngest set does not commonly cross older joints, probably because these older joints are opening with uplift. The youngest set of joints $\left(\mathrm{J} 8 / \mathrm{J} 8^{*}\right)$ has only T-junctions. 
6) Joints can cross other joints at very small angles, down to $5^{\circ}$, without deflection. This is interpreted to mean that such older joints were not prone to reactivation, and were invisible in the stress field.

7) Joints can be polyphase, with segments that belong to different age generations.

\section{Acknowledgements}

Funding: JLU and MP thank the German Science Foundation DFG for funding this project (grants UR 64/17-1).

\section{References}

ALZAYER, Y., EICHHUBL, P. and LAUBACH, S.E. 2015. Non-linear growth kinematics of opening-mode fractures. Journal of Structural Geology, 74, 31-44.

BELAYNEH, M. 2003. Analysis of natural fracture networks in massive and well-bedded carbonates and the impact of these networks on fluid flow in dual porosity modelling. Thesis, Imperial College London (University of London).

BELAYNEH, M. 2004. Palaeostress orientation inferred from surface morphology of joints on the southern margin of the Bristol Channel Basin, UK. Geological Society, London, Special Publications, 231, 243255.

BELAYNEH, M., GEIGER, S. and MATTHÄI, S.K. 2006. Numerical simulation of water injection into layered fractured carbonate reservoir analogs. AAPG Bulletin, 90, 1473-1493.

BERKOWITZ, B. 2002. Characterizing flow and transport in fractured geological media: A review. Advances in Water Resources, 25, 861-884.

BONNET, E., BOUR, O., ODLING, N.E., DAVY, P., MAIN, I., COWIE, P. and BERKOWITZ, B. 2001. Scaling of fracture systems in geological media. Reviews of Geophysics, 39, 347-383.

BOURNE, S. J. and WILLEMSE, E. J. M. 2001. Elastic stress control on the pattern of tensile fracturing around a small fault network at Nash Point, UK. Journal of Structural Geology 23, 1753-1770

BROOKS, M., TRAYNER, P.M. and TRIMBLE, T.J. 1988. Mesozoic reactivation of Variscan thrusting in the Bristol Channel area, UK. Journal of the Geological Society, 145, 439-444.

BOURNE, S.J. 2003. Contrast of elastic properties between rock layers as a mechanism for the initiation and orientation of tensile failure under uniform remote compression. Journal of Geophysical Research: Solid Earth, 108, p. 2395

CAPUTO, R. and HANCOCK, P.L. 1999. Crack-jump mechanism and its implications for stress cyclicity during extension fracturing. Journal of Geodynamics, 27, 45-60.

CHADWICK, R.A. 1993. Aspects of basin inversion in southern Britain. Journal of the Geological Society, London, 150, 311-322. 
COELHO, S., PASSCHIER, C., MARQUES, F. 2006. Riedel-shear control on the development of pennant veins: Field example and analogue modelling. Journal of Structural Geology, 28, 1658-1669.

COSGROVE, J.W. 2001. Hydraulic fracturing during the formation and deformation of a basin: a factor in the dewatering of low-permeability sediments. AAPG Bulletin, 85, 737-748.

DART, C.J., MCCLAY, K. and HOLLINGS, P.N. 1995. 3D analysis of inverted extensional fault systems, southern Bristol Channel basin. In: Buchanan J.G. and Buchanan P.G. Basin Inversion, (ed.), Geological Society Special, 88, 393-413.

DAVISON, I. 1995. Fault slip evolution determined from crack-seal veins in pull-aparts and their implications for general slip models. Journal of Structural Geology, 17, 1025-1034.

De DREUZY, J.-R., MÉHEUST, Y. and PICHOT, G. 2012. Influence of fracture scale heterogeneity on the flow properties of three-dimensional discrete fracture networks (DFN). Journal of Geophysical Research: Solid Earth, 117, B11207

DERSHOWITZ, W.S. and HERDA, H.H. 1992. Interpretation of fracture spacing and intensity. In: The 33th U.S. Symposium on Rock Mechanics (USRMS), p. 10, Santa Fe, New Mexico.

DYER, R. 1998. Using joint interactions to estimate paleostress ratios. Journal of Structural Geology, 10, 685699.

ENGELDER, T. and PEACOCK, D.C.P 2001. Joint development normal to regional compression during flexural-flow folding: the Lilstock buttress anticline, Somerset, England. Journal of Structural Geology, 23, 259-277.

FOSSEN, H. 2016. Structural Geology. Cambridge University Press, 510pp.

GILLESPIE, P., MONSEN, E., MAERTEN, L., HUNT, D., THURMOND, J. and TUCK, D. 2011. Fractures in carbonates: from digital outcrops to mechanical models. Society for Sedimentary Geology, 10, 137-147.

GLEN, R.A., HANCOCK, P.L. and WHITTAKER, A. 2005. Basin inversion by distributed deformation: the southern margin of the Bristol Channel Basin, England. Journal of Structural Geology, 27, 2113-2134.

GONÇALVES DA SILVA, B. and EINSTEIN, H. H. 2013. Modeling of crack initiation, propagation and coalescence in rocks. International Journal of Fracture 257563978. DOI 10.1007/s10704-013-9866-8

KELLY, R.G., SANDERSON, D.J. and PEACOCK, D.C.P. 1998. Linkage and evolution of conjugate strike-slip fault zones in limestones of Somerset and Northumbria. Journal of Structural Geology, 20, 1447-1493.

KELLY, P.G., PEACOCK, D.C.P, SANDERSON, D.J. and MCGURK, A.C. 1999. Selective reversereactivation of normal faults, deformation around reverse-reactivated faults in the Mesozoic of the Somerset coast. Journal of Structural Geology, 21, 493-509.

KOLARI, K. 2017. A complete three-dimensional continuum model of wing-crack growth in granular brittle solids. International Journal of Solids and Structures 115-116, 27-42.

LAUBACH, S.E., FALL, A., COPLEY, L.K., MARRETT, R. and WILKINS, S.K. 2016. Fracture porosity creation and persistence in a basement-involved Laramide fold, Upper Cretaceous Frontier Formation, Green River Basin, USA. Geological Magazine, 153, 887-910.

LAUBACH, S.E., LANDER, R.H., CRISCENTI, L.J. ANOVITZ, L.M., URAI, J.L., POLLYEA, R.M., HOOKER, J.N., NARR, W. EVANS, M.A., KERISIT, S.N., OLSON, J.E., DEWERS, T., FISHER, D., BODNAR, R., EVANS, B., DOVE, P., BONNELL, L.M., MARDER, M.P. and PYRAK-NOLTE, L. 2019. The Role of Chemistry in Fracture Pattern Development and Opportunities to Advance Interpretations of Geological Materials. Reviews of Geophysics, 57, 1065-1111. 
LONG, J.C.S. and WITHERSPOON, P.A. 1985. The relationship of the degree of interconnection to permeability in fracture networks. Journal of Geophysical Research: Solid Earth, 90, 3087-3098.

LOOSVELD, R.J.H. and FRANSSEN, R.C.M.W. 1992. Extensional vs. shear fractures: implications for reservoir characterisation. Society of Petroleum Engineers, SPE 25017, 23-30. Nemčok and Gayer 1996

LORENZ, J. C., STERLING, J. L., SCHECHTER, D. S., WHIGHAM, C. L., and JENSEN, J. L. (2002). Natural fractures in the Spraberry Formation, Midland basin, Texas: The effects of mechanical stratigraphy on fracture variability and reservoir behavior. AAPG Bulletin, 86(3), 505-524.

MAERTEN, L, MAERTEN, F, LEJRI, M. 2018. Along fault friction and fluid pressure effects on the spatial distribution of fault-related fractures Journal of Structural Geology, 108, 198-212.

MANDL, G. 2005. Rock joints: their mechanical genesis. Springer-Verlag, 221pp.

MENEGONI, N., MEISINA, C., PEROTTI, C. and CROZI, M. 2018. Analysis by UAV Digital Photogrammetry of Folds and Related Fractures in the Monte Antola Flysch Formation (Ponte Organasco, Italy). Geosciences, 8, 299.

NEMČOK, M., GAYER, R. and MILIORIZOS, M. 1995. Structural analysis of the inverted Bristol Channel Basin: implications for the geometry and timing of fracture porosity. In: Buchanan, J.G. and Buchanan, P.G., (ed.), Basin Inversion. Geological Society, London, Special Publications, 88, 355-392.

NEMČOK, M. and GAYER, R. 1996. Modelling palaeostress magnitude and age in extensional basins: a case study from the Mesozoic Bristol Channel Basin, U.K. Journal of Structural Geology, 18, 1301-1314.

NYBERG, B., NIXON, C. W. and SANDERSON, D. J. 2018. NetworkGT: A GIS tool for geometric and topological analysis of two-dimensional fracture networks. Geosphere, 14(4), 1618-1634

OLSON, J.E., LAUBACH, S.E. and LANDER, R.H. 2009. Natural fracture characterization in tight gas sandstones: Integrating mechanics and diagenesis. AAPG Bulletin, 93, 1535-1549.

PEACOCK, D.C.P. and SANDERSON, D.J. 1991. Displacements, segment linkage and relay ramps in normal fault zones. Journal of Structural Geology, 13, 721-733.

PEACOCK, D.C.P. and SANDERSON, D.J. 1994. Geometry and development of relay ramps in normal fault systems. AAPG Bulletin, 78, 147-165.

PEACOCK, D.C.P. and SANDERSON, D.J. 1995. Strike-slip relay ramps. Journal of Structural Geology, 17 , 1351-1360.

PEACOCK, D.C.P. 2001. The temporal relationship between joints and faults. Journal of Structural Geology, 23, 329-341.

PEACOCK, D.C.P. 2004. Differences between veins and joints using the example of the Jurassic limestones of Somerset. In: Cosgrove J.W. and Engelder T. The Initiation, Propagation, and Arrest of Joints and Other Fractures, (ed.), Geological Society, London, Special Publications, 231, 209-221.

PEACOCK, D.C.P., SANDERSON, D.J. and ROTEVATN, A. 2018. Relationships between fractures. Journal of Structural Geology, 106, 41-53.

PENROSE, L. S. and PENROSE, R. 1958. Impossible objects: a special type of visual illusion. British Journal of Psychology, 49, 31-33.

PHILIP, Z.G., JENNINGS, J.W. Jr., OLSON, J.E., LAUBACH, S.E., and HOLDER, J. 2005. Modeling coupled fracture-matrix fluid flow in geomechanically simulated fracture networks: SPE Reservoir Evaluation and 
POLLARD, D.D and AYDIN, A. 1988. Progress in understanding jointing over the past century. GSA Bulletin $100,1181-1204$

POLLYEA, R.M. and FAIRLEY, J.P. 2011. Estimating surface roughness of terrestrial laser scan data using orthogonal distance regression. Geology, 39, 623-626.

PRICE, N.J. and COSGROVE, J.W. 1990. Analysis of Geological Structures. Cambridge University Press, $502 \mathrm{pp}$.

PYRAK-NOLTE, L.J. and DePAOLO, D.J. 2015. Controlling Subsurface Fractures and Fluid Flow: A Basic Research Agenda. United States. https://doi.org/10.2172/1283189

RAWNSLEY, K.D., PEACOCK, D.C.P., RIVES, T. and PETIT. J.-P. 1998. Joints in the Mesozoic sediments around the Bristol Channel Basin. Journal of Structural Geology, 20, 1641-1661.

RENSHAW, C.E. and POLLARD, D.D. 1995. An experimentally verified criterion for propagation across unbounded frictional interfaces in brittle, linear elastic materials. International Journal of Rock Mechanics and Mining Sciences and Geomechanics Abstracts, 32, 237-249.

Spruženiece, L., Späth, M., Urai, J. L., Ukar, E., Selzer, M., Nestler, B., Schwedt, A. 2020. Formation of wideblocky calcite veins by extreme growth competition. Journal of the Geological Society, 178, jgs2020-104, https://doi.org/10.1144/jgs2020-104.

Spruženiece, L., Späth, M., Urai, J. L., Ukar, E., Selzer, M., Nestler, B. 2021. Wide-blocky veins explained by dependency of crystal growth rate on fracture surface type: Insights from phase-field modeling: Geology, 49, p. XXX-XXX, https://doi.org/10.1130/G48472.1

TSANG, C.-F. and NERETNIEKS, I. 1998. Flow channeling in heterogeneous fractured rocks. Reviews of Geophysics, 36, 275-298.

TWISS, R.J. and MOORES, E.M. 1992. Structural geology. Freeman, New York, 531pp.

VIRGO, S., ARNDT, M., SOBISCH, Z., URAI, J.L. 2013. Development of fault and vein networks in a carbonate sequence near Hayl al-Shaz, Oman Mountains. GeoArabia, 18, 99-136.

VIRGO, S. ABE, S. and URAI, J.L. 2014. The evolution of crack seal vein and fracture networks in an evolving stress field: Insights from Discrete Element Models of fracture sealing. Journal of Geophysical Research: Solid Earth, 119, 8708-8727.

VIRGO, S. ABE, S. and URAI, J.L. 2016. The influence of loading conditions on fracture initiation, propagation, and interaction in rocks with veins: Results from a comparative Discrete Element Method study. Journal of Geophysical Research: Solid Earth, 121, 1730-1738. models and field data. Journal of Geophysical Research: Solid Earth, 102, 675-692. 

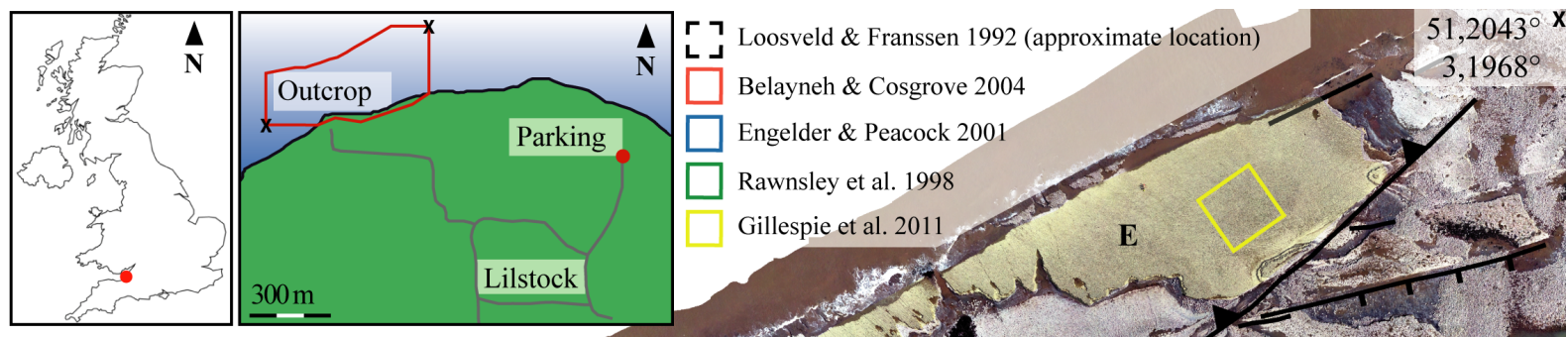

.

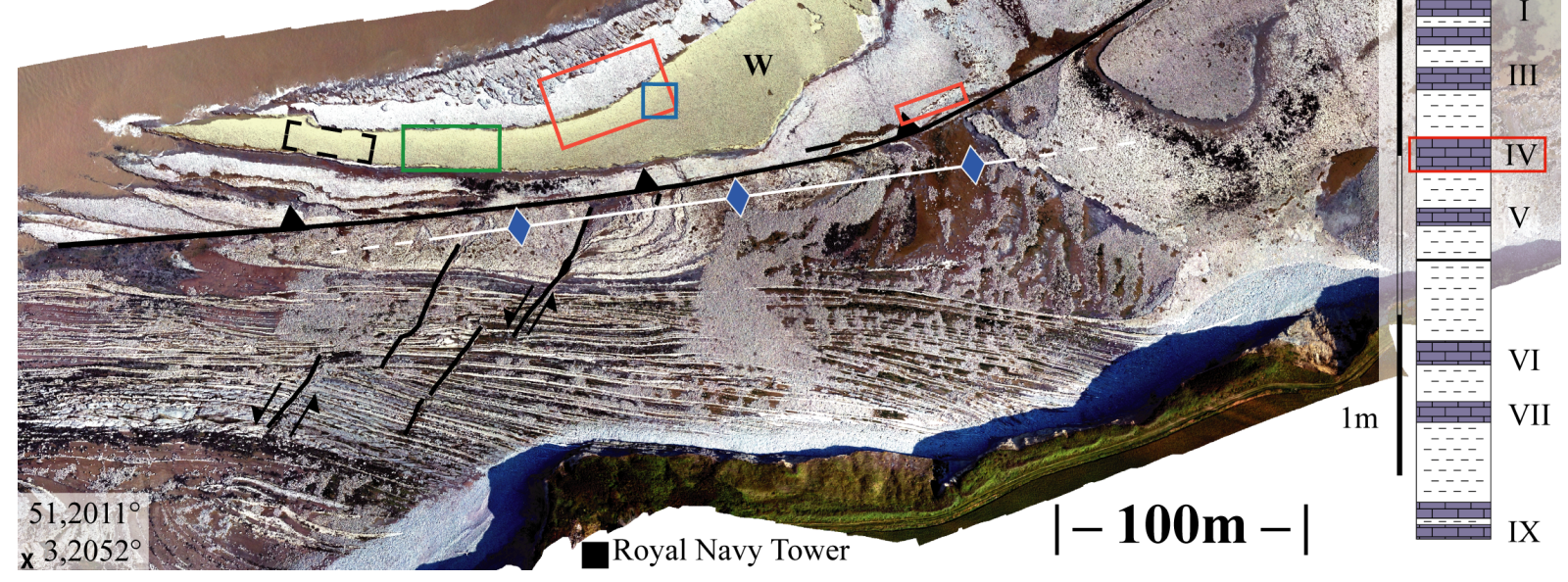

Fig. 1. Overview of the main part of the Lilstock Benches in a merged digital image, taken from $100 \mathrm{~m}$ altitude. Bench IV, an outcropping part of layer IV is highlighted in yellow, the main faults in black, the anticline in white with blue arrows. W and E: Areas W and E of Bench IV. Locations of previous work on joints in the literature shown as coloured rectangles. Location of Lilstock in the UK and the outcrop at Lilstock Beach, outlined in red shown in insets at top left. Stratigraphic column of the clay and limestone benches shown at bottom right, highlighting layer IV. 

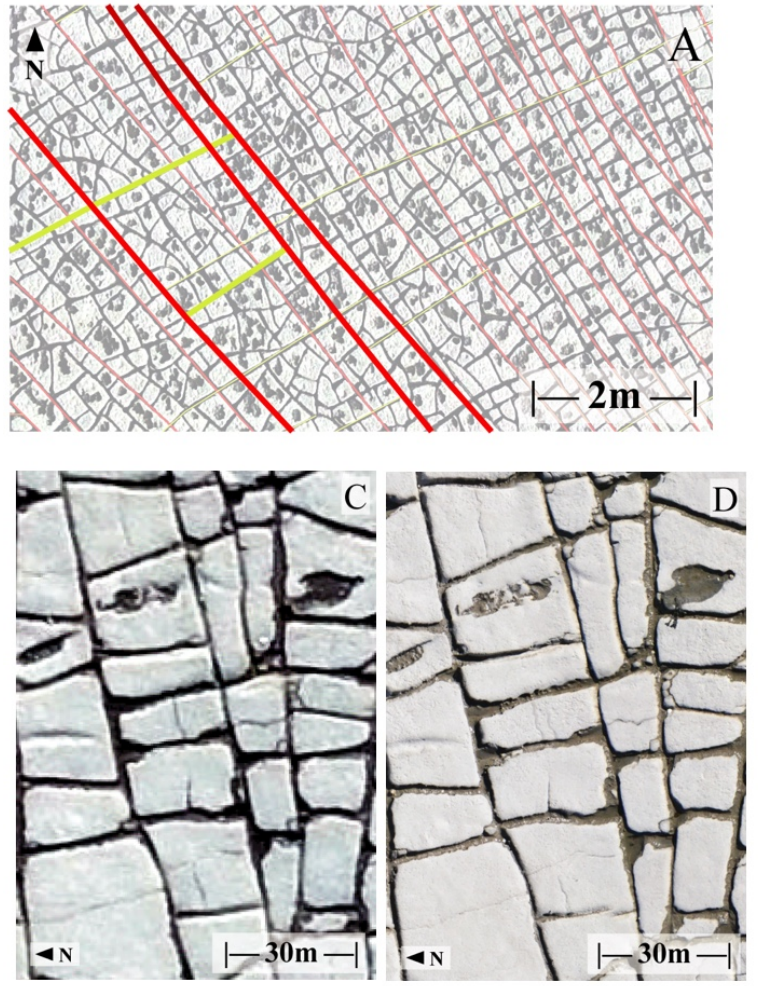
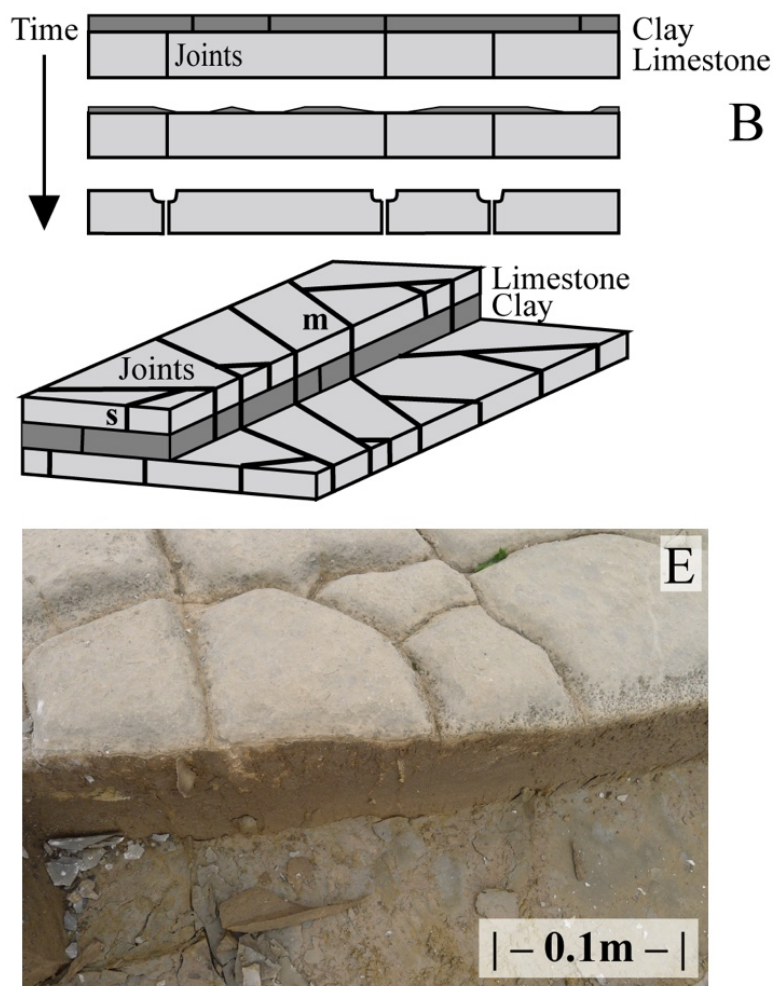

652 Fig. 2. (a) example of $\mathrm{T}$ - and $\mathrm{X}$-junctions between $\mathrm{J} 1 *$ (red) and J4* (yellow) joints in Area E. (b) weathering process erodes joints to a "U" shape that makes them visible from a distance. Joint can be formed within only one layer (s) or can cross into multiple layers above and below (m). (c) resolution of $7.4 \mathrm{~mm}$ pixel size used for this study compared to (d) the resolution of field photography with $2.2 \mathrm{~mm}$ pixel size. (e) field photo of typical eroded

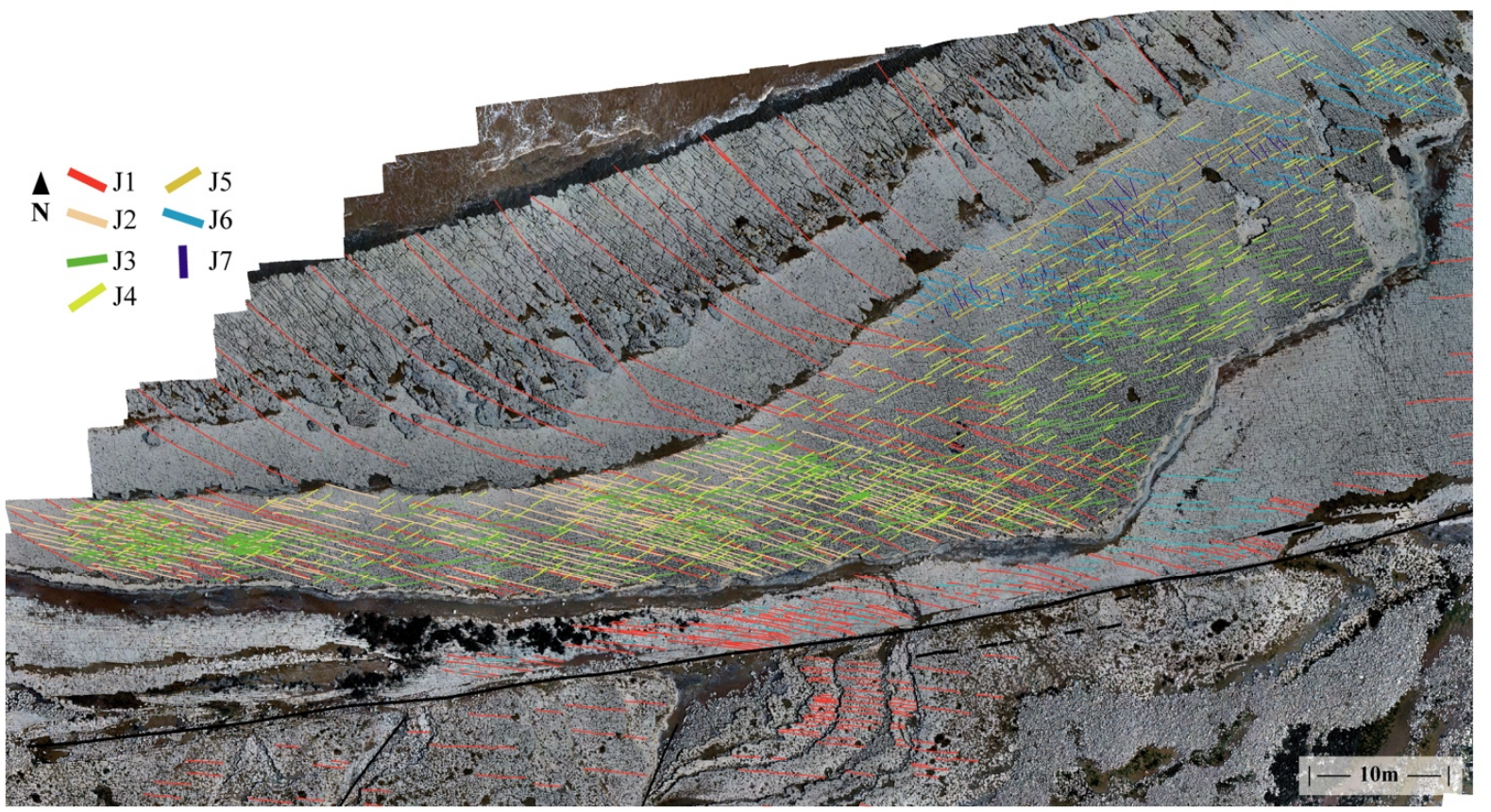

Fig. 3. Overview of Area W with all mapped sets marked in colour, except for the youngest, J8. Visible are J1 and 

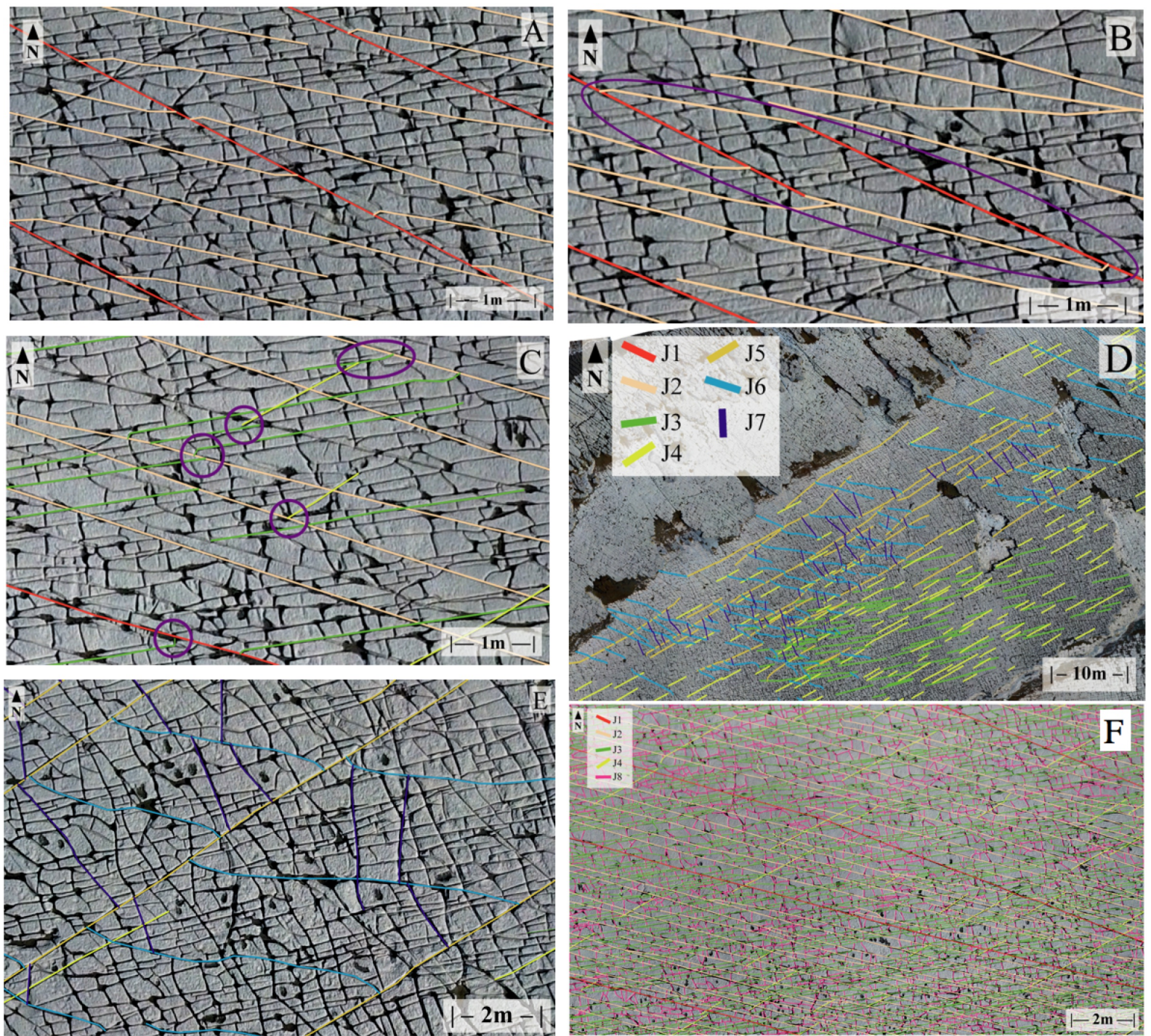

661 Fig. 4. Interaction of different sets of joints in Area W. Only the joints of sets discussed have been highlighted in colour for clarity. (a) J2 joints (beige) of Area $\mathrm{W}$ abut on $\mathrm{J} 1$ joints (red). $\mathrm{J} 3$ and $\mathrm{J} 4$ joints are visible but have not been colour coded. (b) rhomb shaped form (marked by purple oval) defined by J1 and J2 joints, caused by mutual impingement, probably due to reactivation of $\mathrm{J} 1$ joints during formation of $\mathrm{J} 2$ joints. (c) abutment relations of sets J1 (red), J2 (beige), J3 (green) and J4 (yellow) joints in Area W. Purple circles show abutment. (d) enlarged northeastern part of Area $\mathrm{W}$ with locally occurring sets: J5, J6 and J7. The more widely distributed sets J3 and J4 are also present, while $\mathrm{J} 1$ and $\mathrm{J} 2$ are not developed in this location. (e) strongly curved J6 joints (light blue) impinging on J5 (dark yellow). J7 joints dark blue. Curvature is such that it increases the impingement angle. (f) section of outcrop with all joints highlighted: J1-J4 and J8 (enlarged in Fig. S2). Location shown in Fig. 5b. 


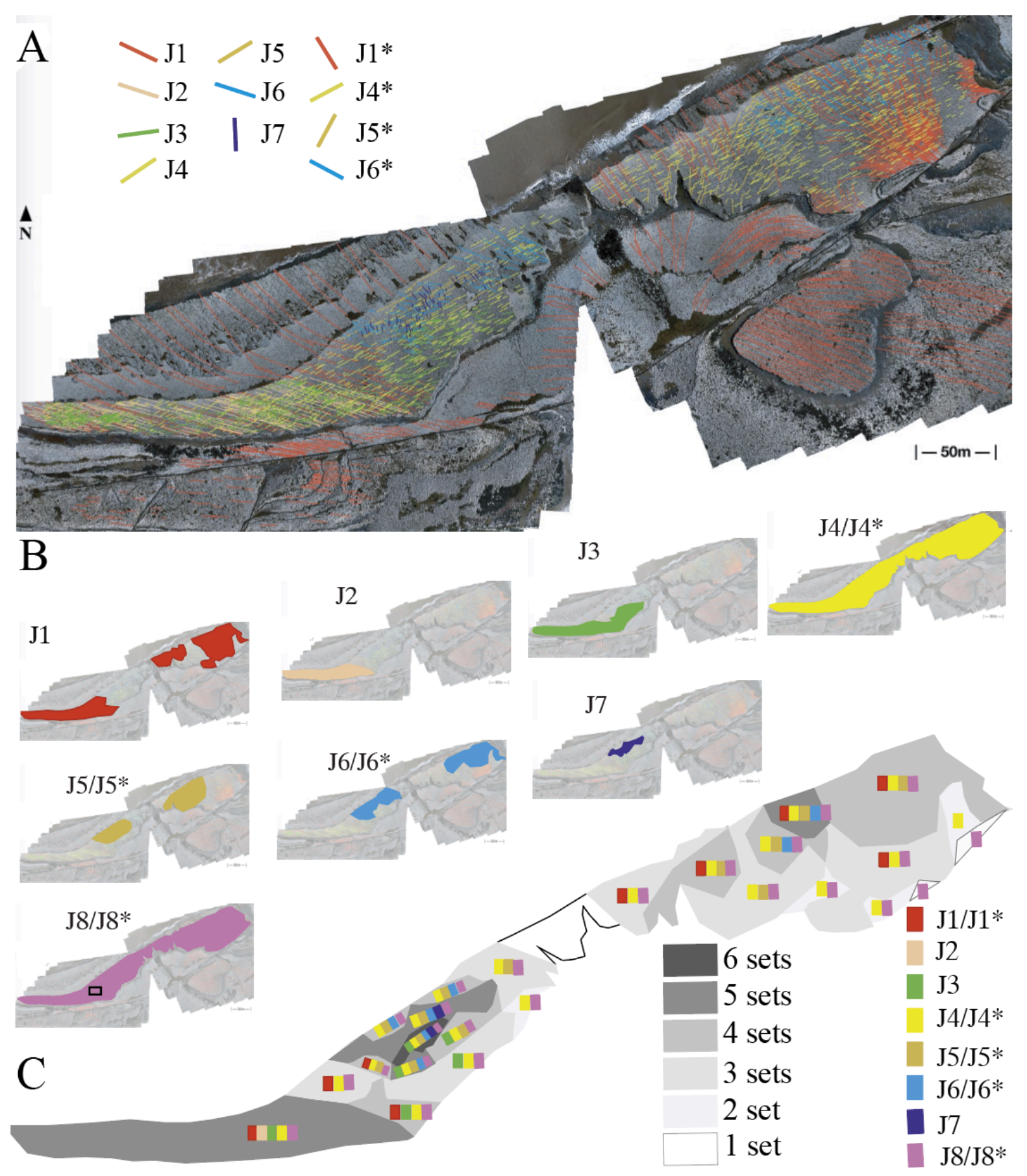

671 Fig. 5. Distribution of all joints over Bench IV. (a) general distribution of joint sets, youngest joint set J8/J8* not 672 shown. Enlargement with higher resolution in Supplementary Fig. S1. (b) spatial distribution of the individual 673 sets. The area with mapped J8 joints of Fig. 4f is marked by a rectangle. (c) approximate distribution of the number 674 of sets present over bench IV. The maximum number of joints in any domain is six, including set J8/J8*. Coloured 675 bars indicate the joint sets present in each domain. 
joint orientation

\section{Area W Area E}
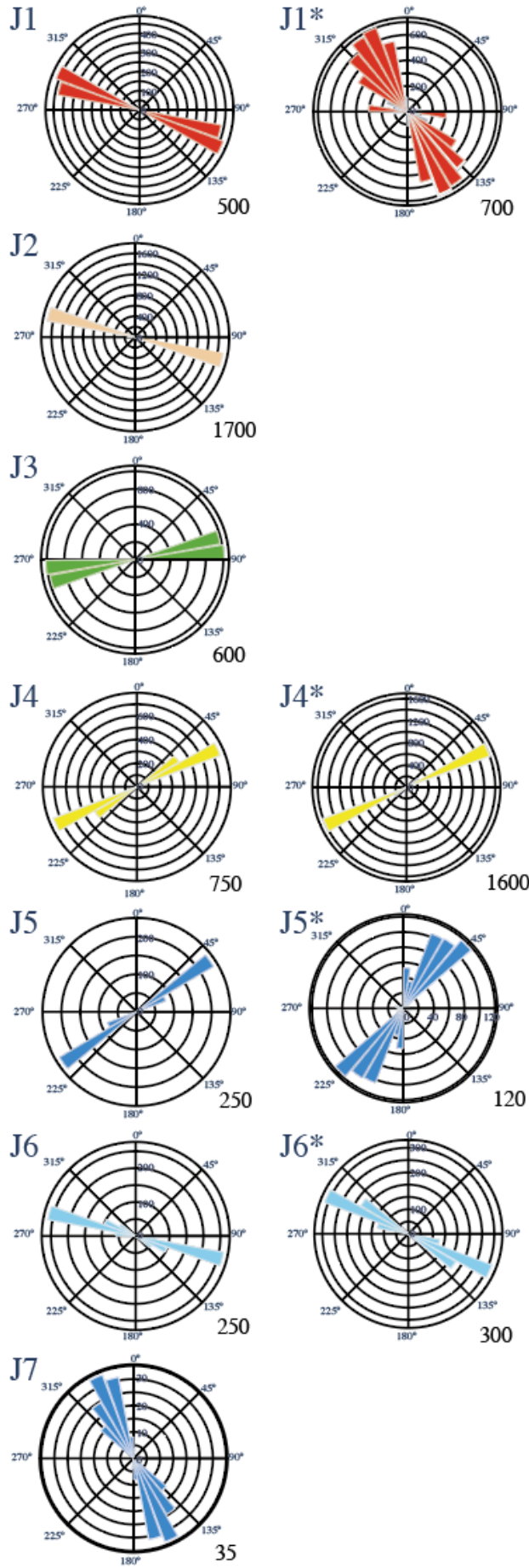

300

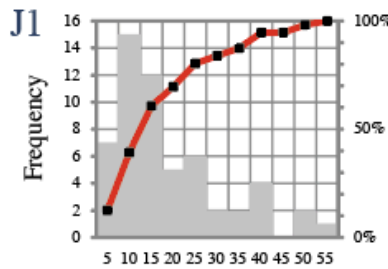

$\mathrm{J} 2$

joint length

Area W

Area E
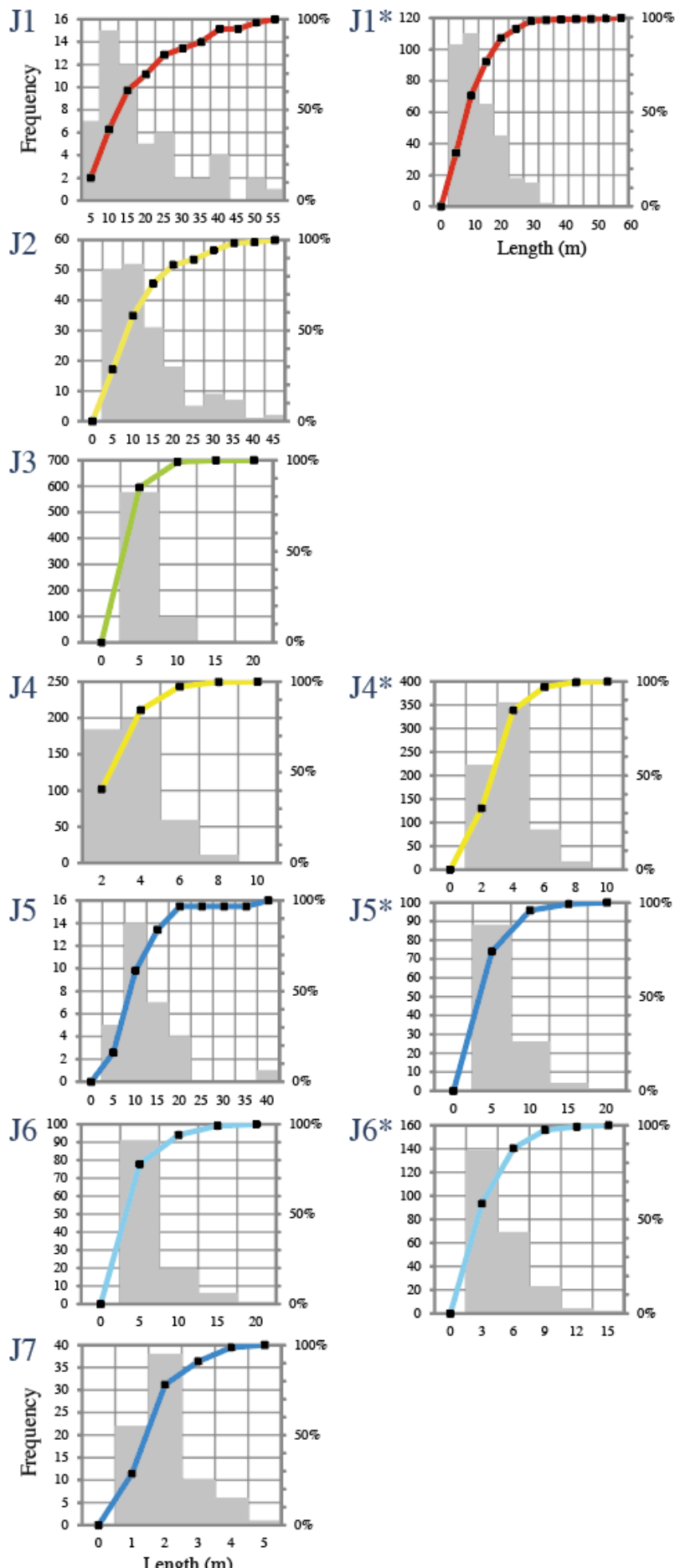

677 Fig. 6. Length-weighted rose diagrams with a bin size of $10^{\circ}$ for joint populations and histogram and cumulative 678 length distribution of joints sorted by set. Data in Table 2. 

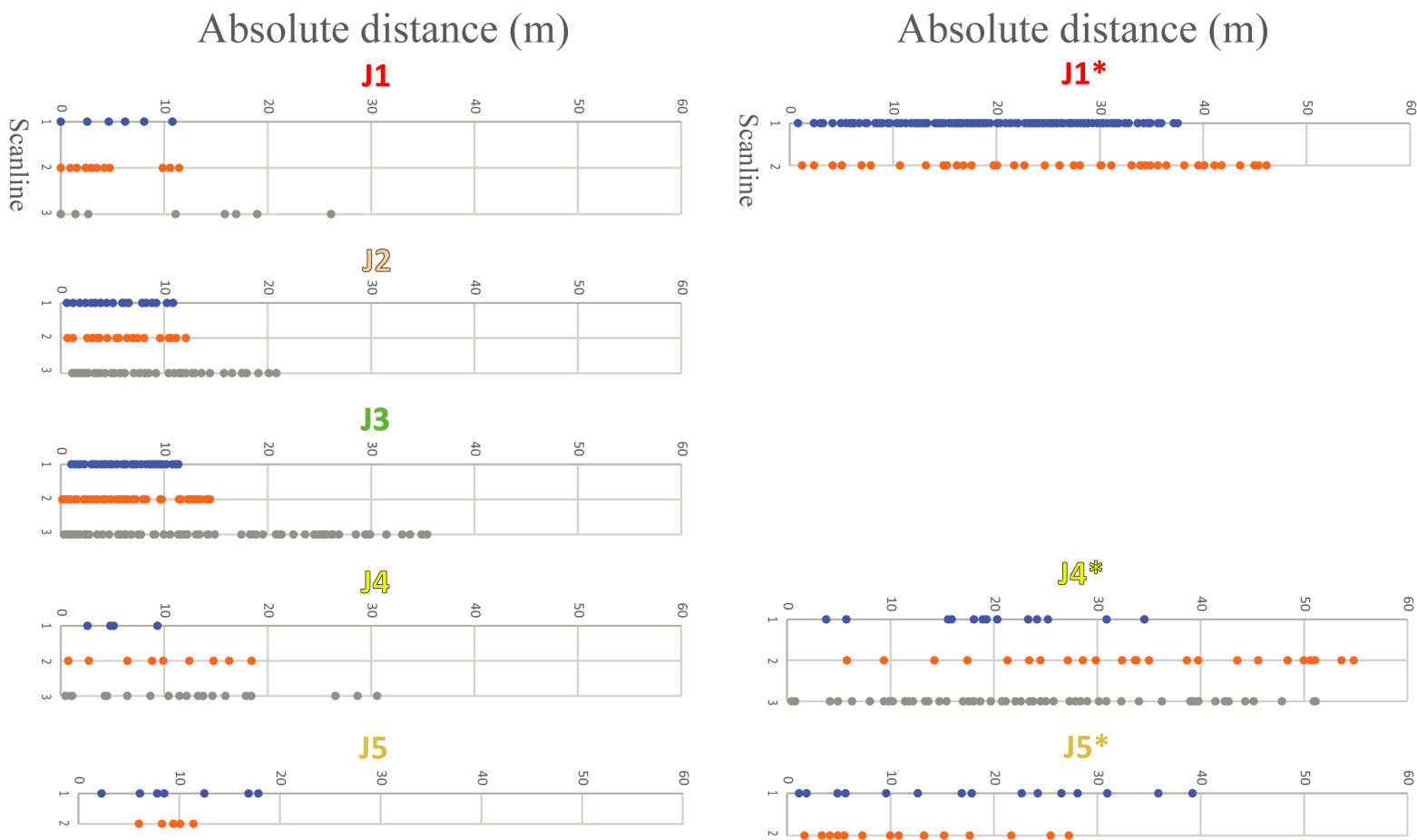

J5*

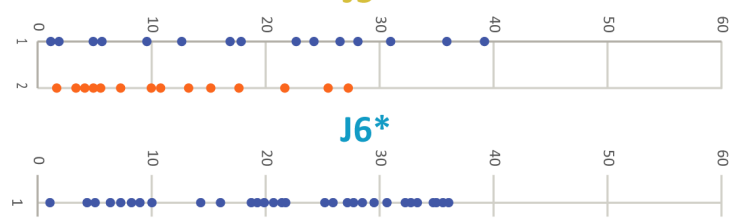

J7

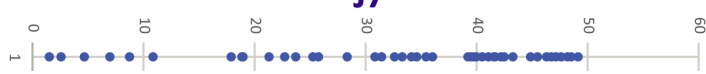

680 Fig. 7. Occurrence of fractures measured in absolute distance $(\mathrm{m})$ from a first fracture at $0 \mathrm{~m}$ along the $\mathrm{x}$-axis.

681 Measurements were done using scanlines oriented $90^{\circ}$ to the average strike direction of the respective joint set.

682 The numbers on the y-axis represent the respective number of the scanline where several lines were used to

683 sample a single joint set. Different colours used within the plots mark different scanlines and have no further

684 meaning. 

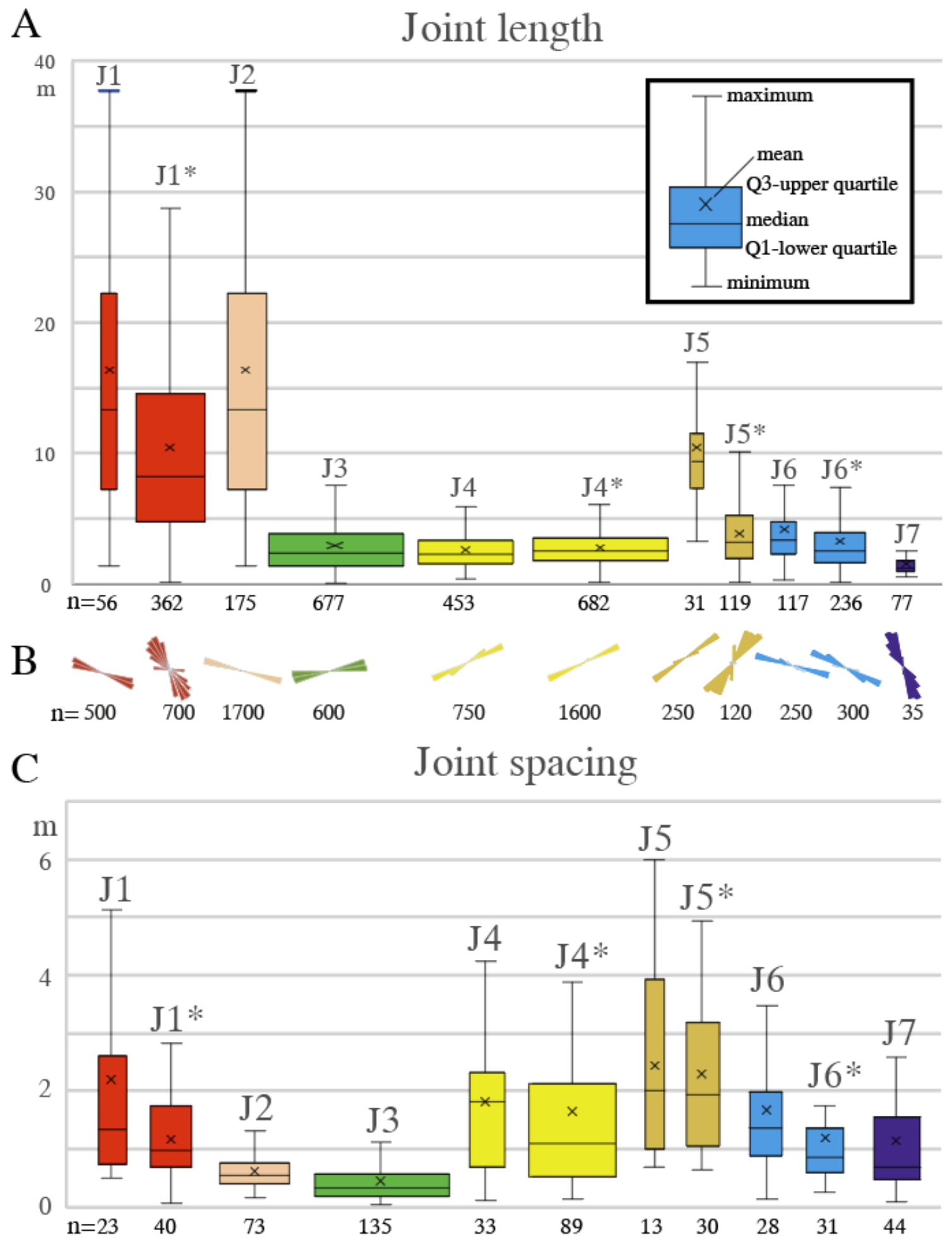

686 Fig. 8. (a) box and whisker plots of joint length for all joint sets, with outliers left out. Inlier explains the plot (b) 687 summarised orientation diagrams of the joint sets, based on Figure 6a, for comparison. (c) box and whisker plots 688 of joint spacing measured along profiles as shown in Figure 7. Cross in the box and whisker diagrams refers to 689 the mean value. 


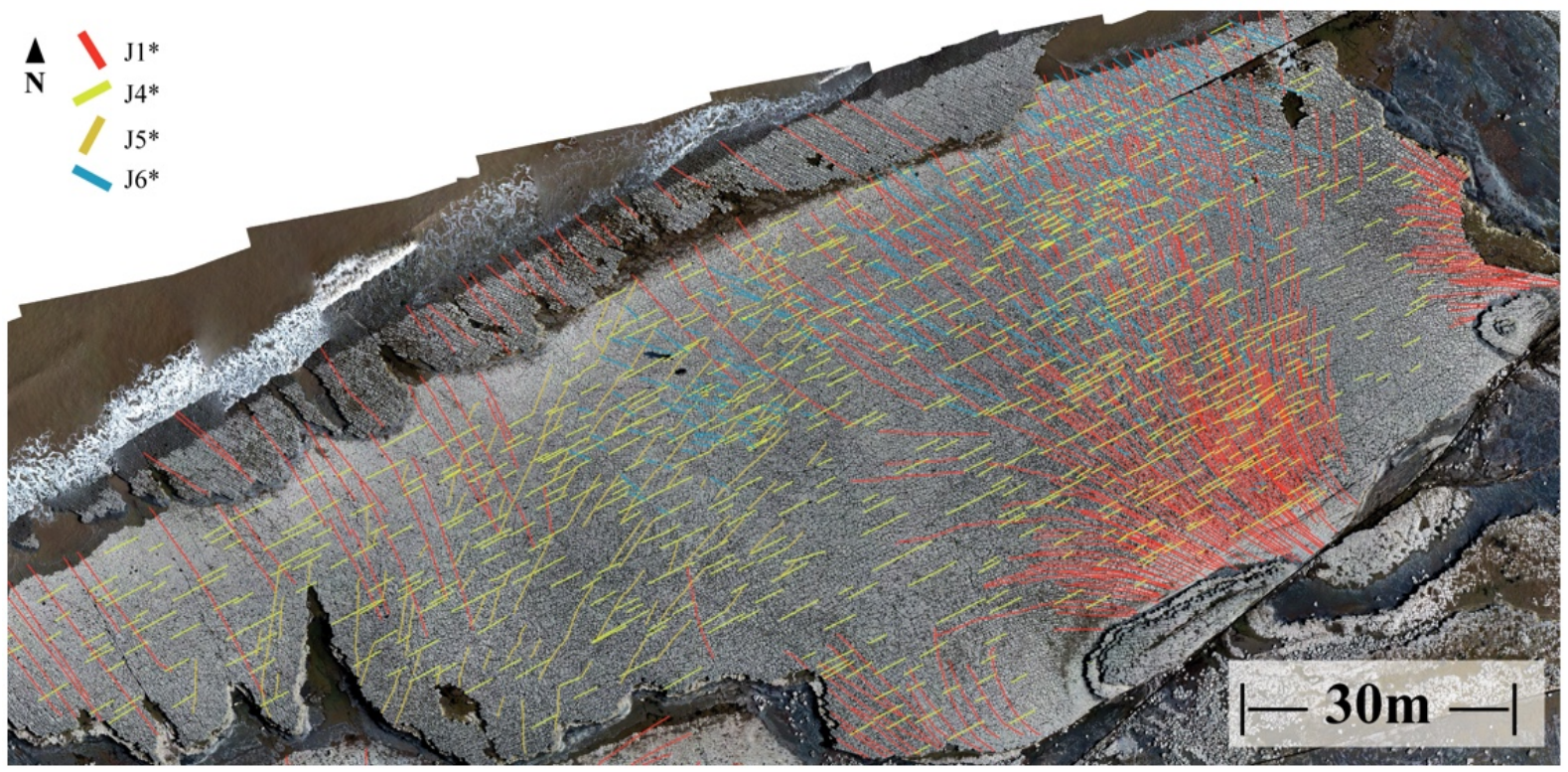

Fig. 9. Overview of Area $\mathrm{E}$ with all mapped joint sets except the youngest $\mathrm{J} 8^{*} . \mathrm{J} 5^{*}$ and $\mathrm{J} 6^{*}$ occur mostly in
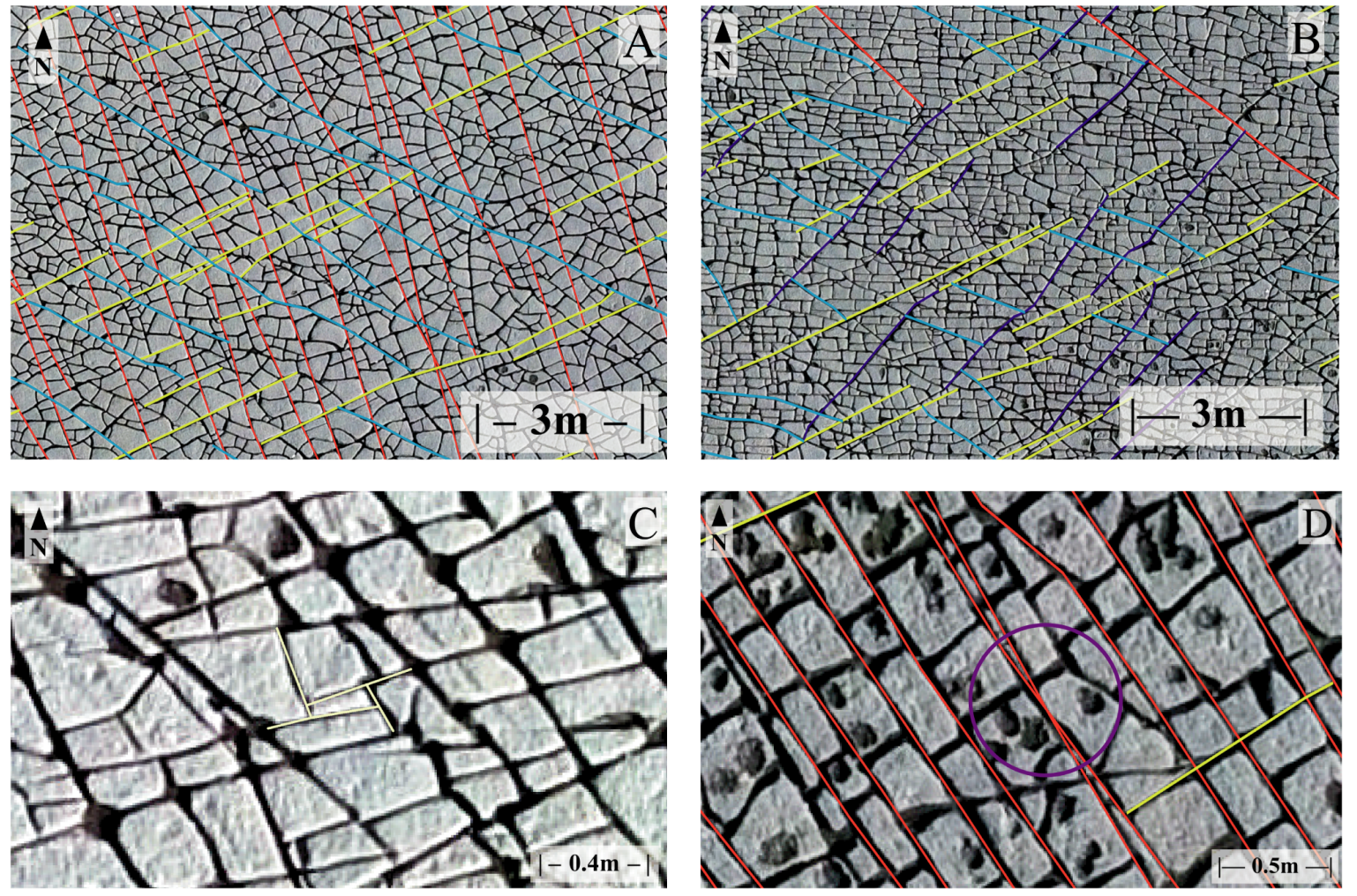

Fig. 10. Interaction of different sets of joints mostly from Area E. Joints of sets discussed have been highlighted in colour for clarity. (a) apparently conflicting abutting relations between $\mathrm{J} 4 *$ (yellow) and J6* (light blue). These sets are abutting each other with equal frequency. (b) J6* (blue) abutting J5* (dark yellow), which abuts to J4* (yellow) resolving the age-relationship. Two J1* joints are also shown. (c) four J8 joints from Area A forming an Escherian paradox through T-intersections that contradict the simple analysis based on sequential joint growth. (d) the smallest angle of crossing joints could be observed between two $\mathrm{J} 1 *$ joints at $5^{\circ}$ (marked by a circle). 


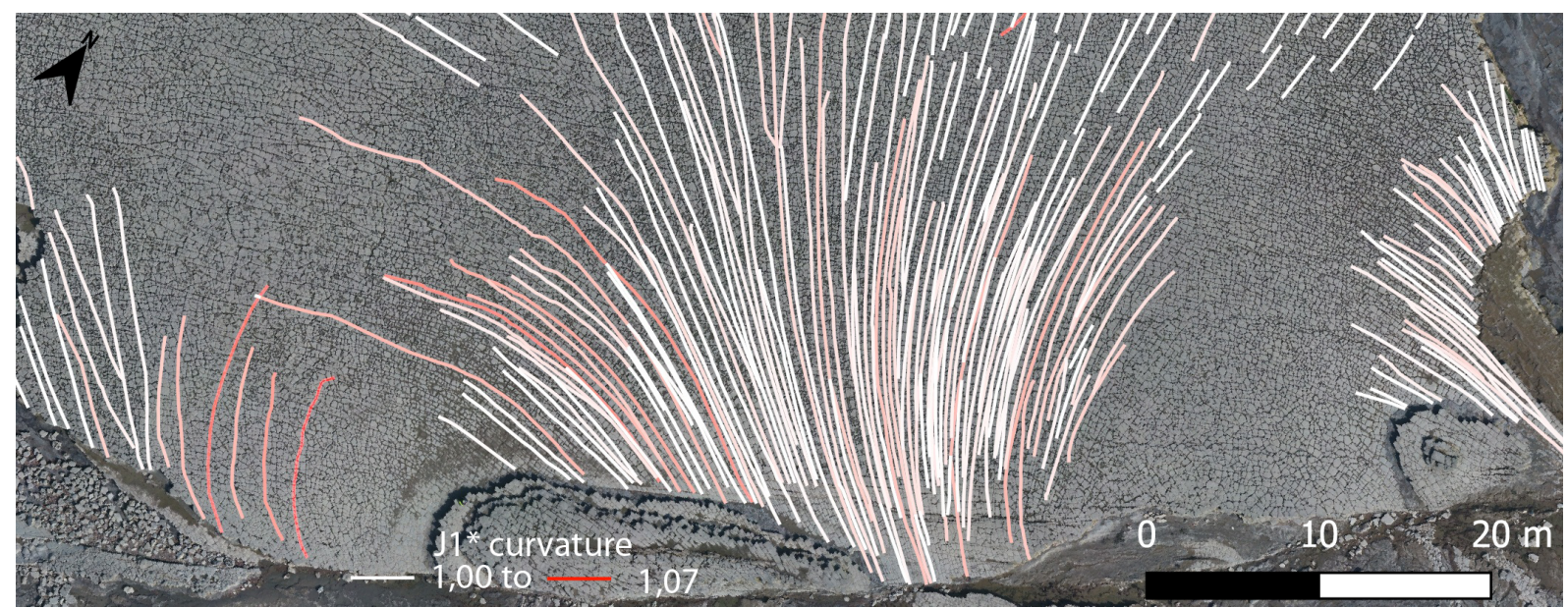

702 Fig. 11. Joint trace curvature map of $\mathrm{J} 1 *$ in Area E. Increasing curvature in indicated by increasingly dark red 703 colour of joints
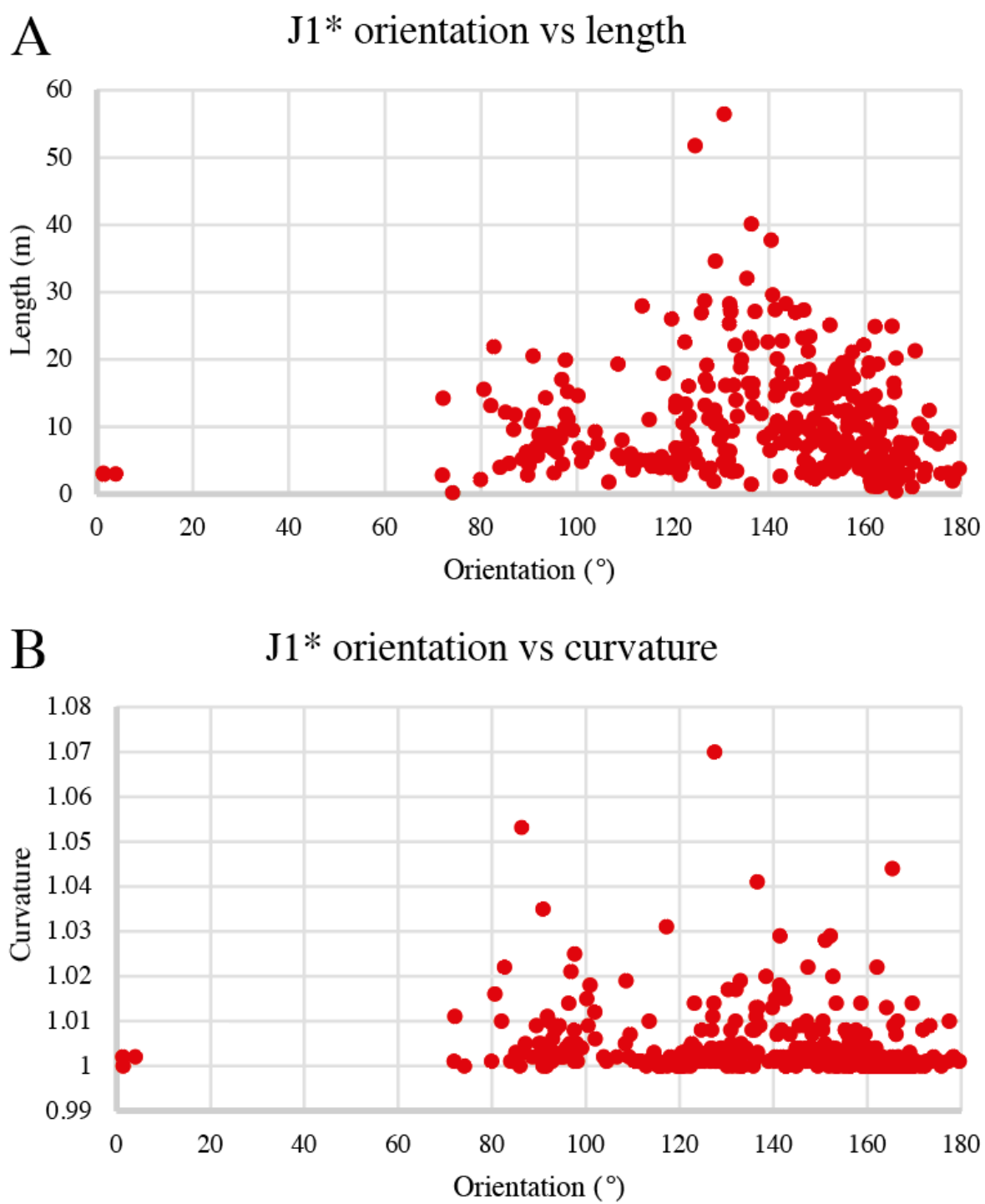

705 Fig. 12. Plots showing (A) the relation of orientation and length and (B) orientation and curvature for $\mathrm{J} 1 *$ joints. 


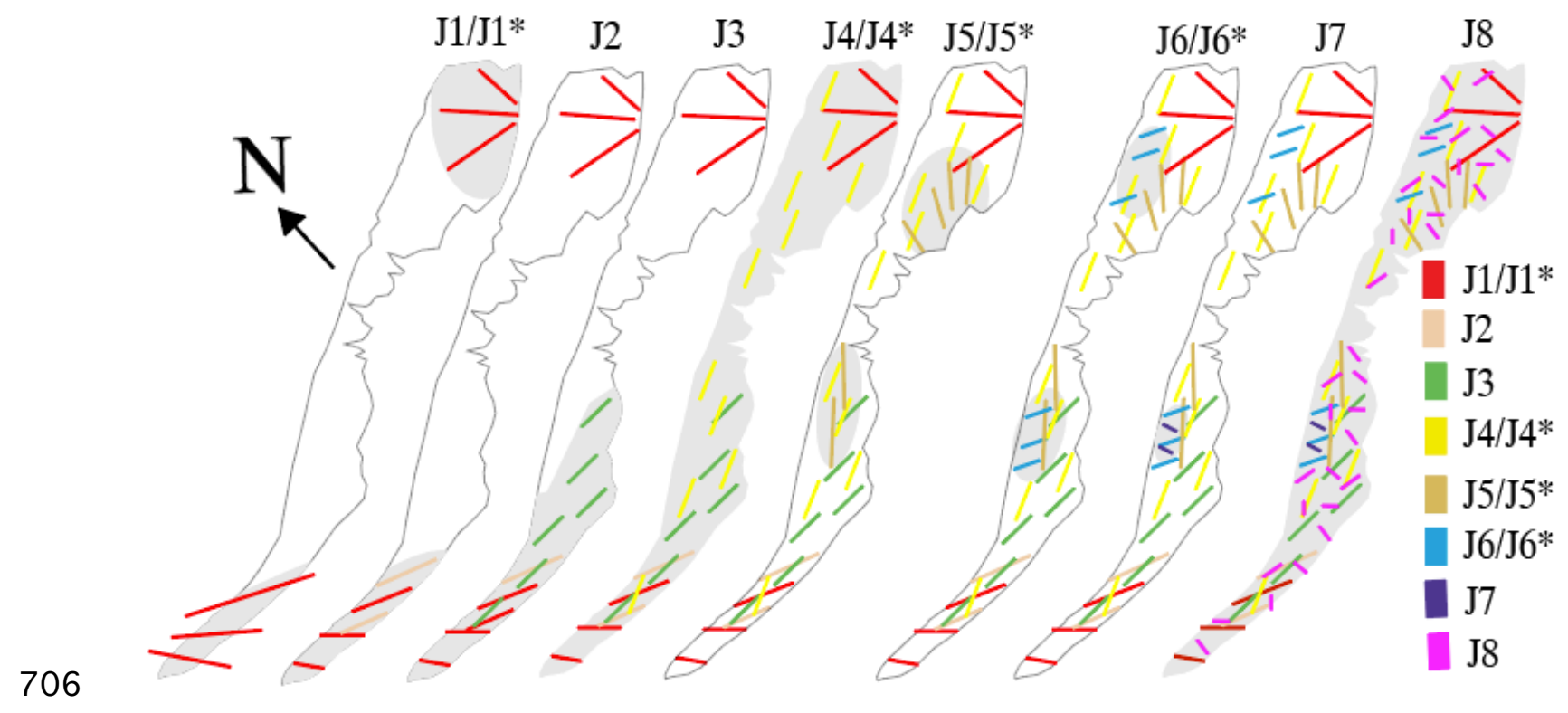

707 Fig. 13. Development of the subsequent joint sets in Bench IV. Coloured bars schematically indicate the 708 orientation and relative length of joint sets. Grey background indicates the area of active development of each set. 709 Domains where joints sets occur are not shown accurately, but approximately, to show trends. 


\begin{tabular}{|c|c|c|c|c|c|c|c|}
\hline \multicolumn{2}{|c|}{ East } & \multicolumn{2}{|c|}{ West } & \multicolumn{4}{|c|}{ Generations in literature } \\
\hline $\begin{array}{l}\text { Generation } \\
\text { Strike } \\
\text { Length }[\mathrm{m}]\end{array}$ & $\begin{array}{l}\text { Curvature } \\
\text { Properties }\end{array}$ & $\begin{array}{l}\text { Generation } \\
\text { Strike } \\
\text { Length [m] }\end{array}$ & $\begin{array}{l}\text { Curvature } \\
\text { Properties }\end{array}$ & $\mathrm{B} \& \mathrm{C}$ & $\mathrm{E} \& \mathrm{P}$ & $\mathrm{L} \& \mathrm{~F}$ & Rea \\
\hline \begin{tabular}{l|}
$\mathrm{J} 1$ \\
$115-120^{\circ}$ \\
$30-50$ \\
\end{tabular} & straight & $\begin{array}{ll}\mathrm{J} 1 * \\
\mathrm{I} & 300-340^{\circ} \\
\mathrm{I} & 10-30\end{array}$ & $\begin{array}{l}\text { fanning out } \\
\text { connected } \\
\text { to fault } \\
\end{array}$ & $\begin{array}{c}\mathrm{J} 1 \\
115- \\
120^{\circ} \\
\end{array}$ & $\begin{array}{c}\mathrm{J} 2 \\
115- \\
120^{\circ} \\
\end{array}$ & 1 & $\begin{array}{c}3 \\
125- \\
130^{\circ} \\
\end{array}$ \\
\hline $\begin{array}{l}\mathrm{J} 2 \\
100-105^{\circ} \\
6-10 \\
\end{array}$ & $\begin{array}{l}\text { straight, curve } \\
\text { into } T \text { junction }\end{array}$ & & & $\begin{array}{c}\mathrm{J} 2 \\
110- \\
115^{\circ} \\
\end{array}$ & $\begin{array}{c}\mathrm{J} 4 \\
95- \\
105^{\circ}\end{array}$ & 2 & $\begin{array}{c}4 \\
100- \\
110^{\circ} \\
\end{array}$ \\
\hline $\begin{array}{l}\mathrm{J} 3 \\
80^{\circ} \\
6-15 \\
\end{array}$ & $\begin{array}{l}\text { straight, } \\
\text { most common }\end{array}$ & & & $\begin{array}{l}\mathrm{J} 3 \\
85- \\
95^{\circ}\end{array}$ & $\begin{array}{l}\mathrm{J} 6 \\
75- \\
85^{\circ}\end{array}$ & $3 \& 4$ & \\
\hline $\begin{array}{l}\mathrm{J} 4 \\
60^{\circ} \\
1-4 \\
\end{array}$ & $\begin{array}{l}\text { straight } \\
\text { consistent }\end{array}$ & $\begin{array}{ll}\mathrm{I} & \mathrm{J} 4 * \\
\mathrm{I} & 60-65^{\circ} \\
\mathrm{I} & 1-6 \\
\end{array}$ & $\begin{array}{l}\text { straight } \\
\text { consistent }\end{array}$ & $\begin{array}{l}\mathrm{J} 4 \\
65- \\
70^{\circ} \\
\end{array}$ & & 5 & \\
\hline $\begin{array}{l}\mathrm{J} 5 \\
55-60^{\circ} \\
10-20\end{array}$ & $\begin{array}{l}\text { lightly curved } \\
\text { local presence }\end{array}$ & $\begin{array}{ll}\mathrm{J} 5 * \\
5-40^{\circ} \\
2-5\end{array}$ & straight & & & & \\
\hline $\begin{array}{l}\mathrm{J6} \\
100-110^{\circ} \\
4-8\end{array}$ & $\begin{array}{l}\text { strongly curved } \\
\text { local presence }\end{array}$ & $\begin{array}{ll}\mathrm{J} 6 * \\
\mathrm{I} \\
110-130^{\circ} \\
1-3\end{array}$ & slightly curved & & & & \\
\hline $\begin{array}{l}\mathrm{J} 7 \\
340-10^{\circ} \\
2-5\end{array}$ & $\begin{array}{l}\text { straight } \\
\text { local presence }\end{array}$ & & & $\begin{array}{c}\mathrm{J} 6 \\
335- \\
345^{\circ}\end{array}$ & & & \\
\hline $\begin{array}{l}\text { J8 } \\
\text { variable } \\
<0.5\end{array}$ & $\begin{array}{l}\text { curvy } \\
\text { irregular }\end{array}$ & $\begin{array}{l}\mathrm{J} 8 * \\
\text { I variable } \\
\text { I }<0.5\end{array}$ & straight & & & & \\
\hline
\end{tabular}

711 Table 1. Joint sets and their characteristics in Areas W and E, as well as the connections that can be observed 712 between sets in both areas. Included at the right side are joint sets described in other publications that can be related 713 to sets identified here. Non assignable sets are omitted, strike-values are given if provided in the literature. B\&C -

714 Belayneh and Cosgrove (2004); E\&P - Engelder and Peacock (2001); L\&F - Loosveld and Franssen (1992); Rea

715 - Rawnsley et al., (1998). 


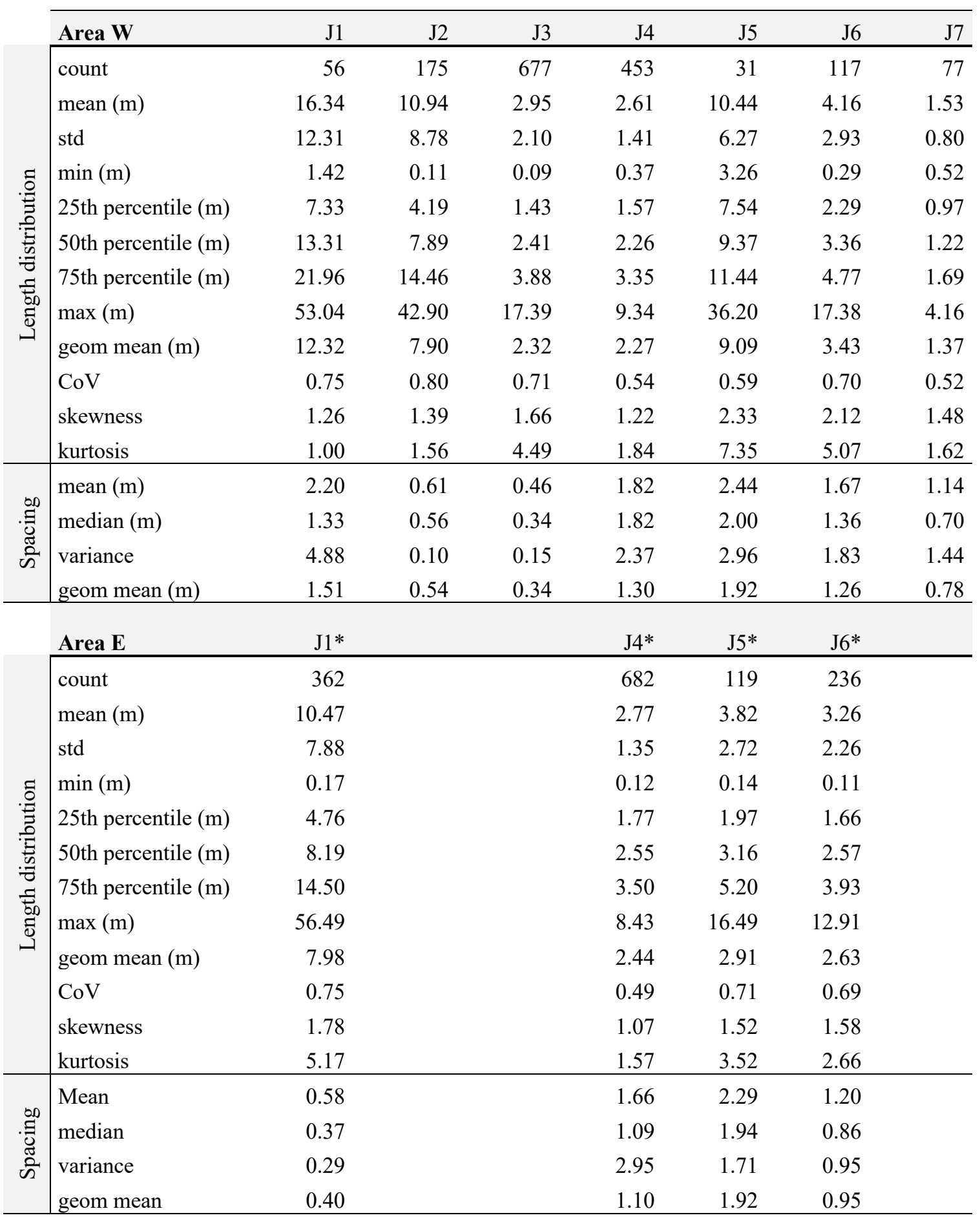

716 Table 2. Length distribution and joint spacing per joint set and area. 


\section{Supplementary Figures}

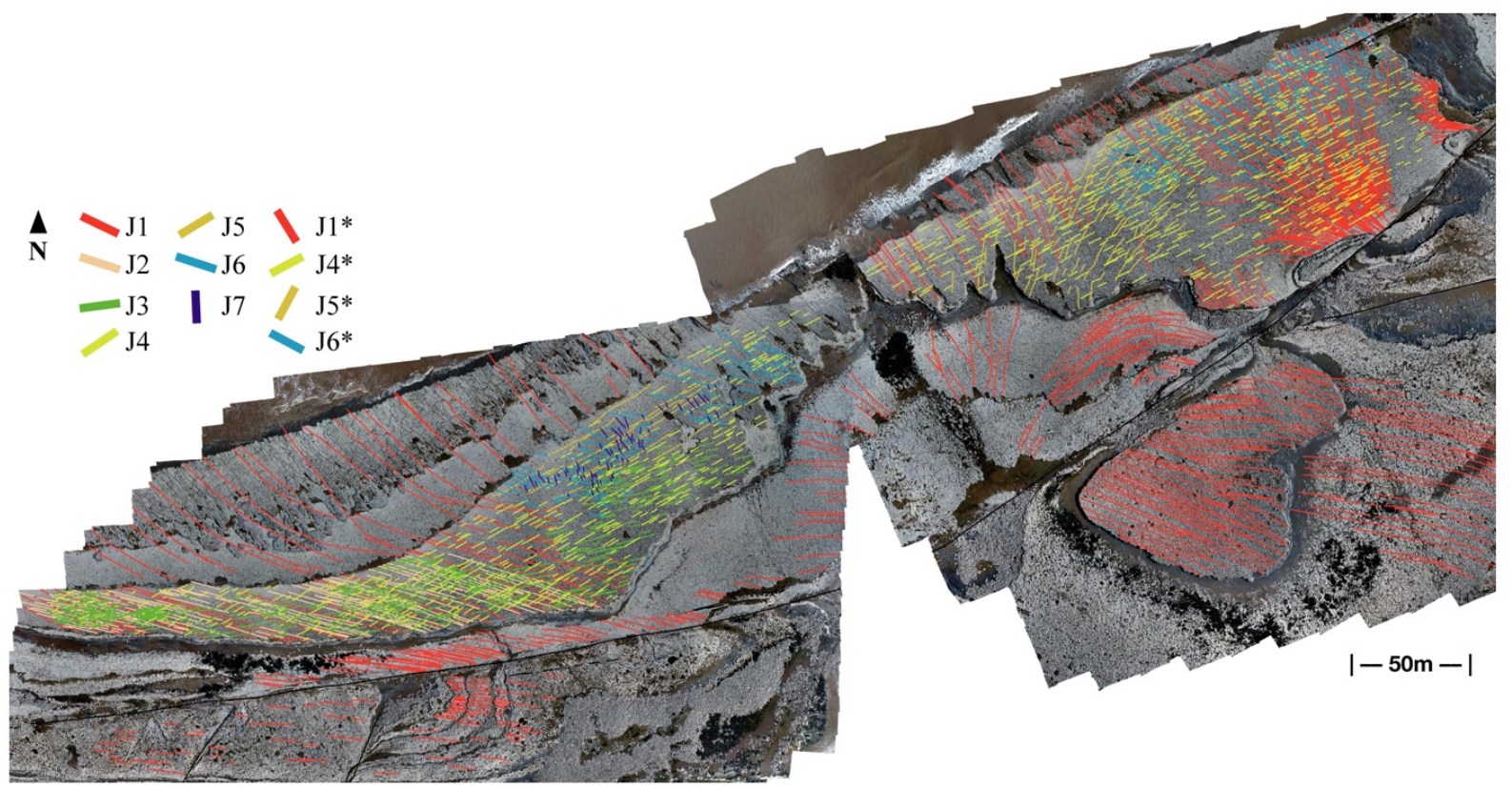

Fig. S1. Overview of the entire outcrop in a high detail image with all sets of mapped joints in Bench IV of the oldest sets are shown.

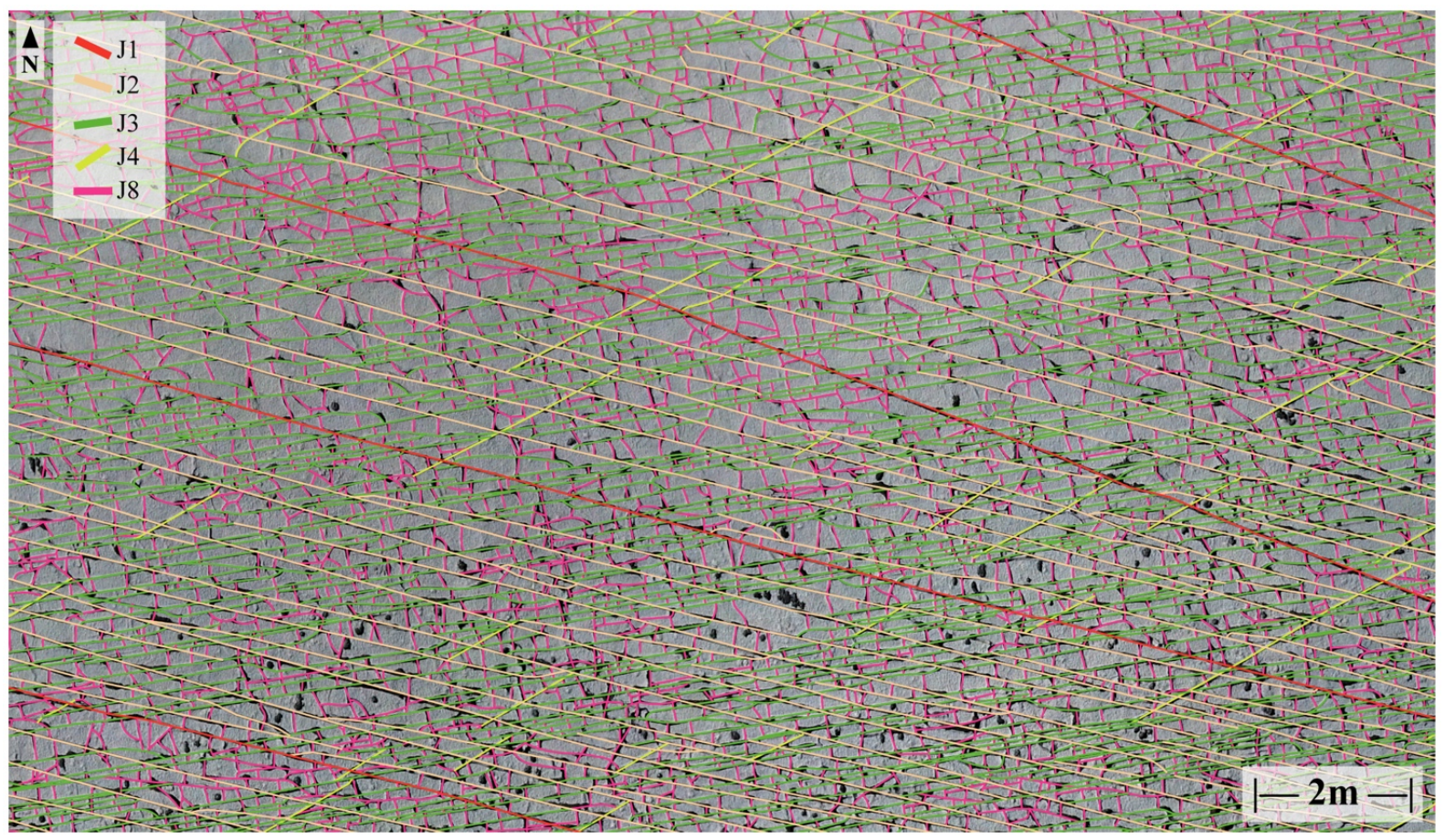

Fig. S2. High resolution image of a small part of Area $\mathrm{W}$ with all existing joints of the locally exposed joint sets mapped and highlighted in colour, including J8. This is an enlargement of Figure 4f. 